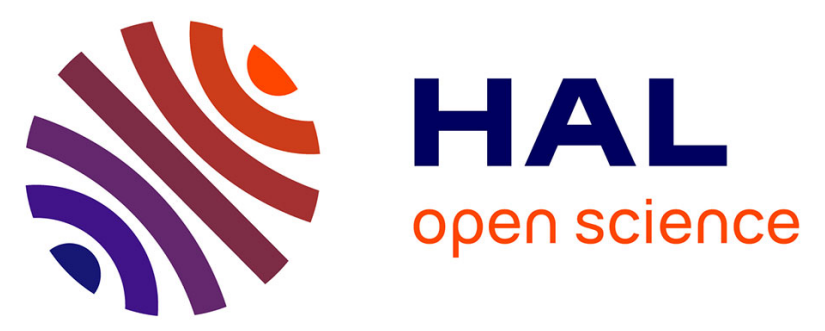

\title{
Soil reinforcement with geosynthetic for localized subsidence problems : experimental and analytical analysis
}

Mouhamad Hassoun, Pascal Villard, Marwan Al Heib, Fabrice Emeriault

\section{To cite this version:}

Mouhamad Hassoun, Pascal Villard, Marwan Al Heib, Fabrice Emeriault. Soil reinforcement with geosynthetic for localized subsidence problems: experimental and analytical analysis. International Journal of Geomechanics, 2018, 18 (10), 10.1061/(ASCE)GM.1943-5622.0001265 . ineris-03319035

\section{HAL Id: ineris-03319035}

https://hal-ineris.archives-ouvertes.fr/ineris-03319035

Submitted on 11 Aug 2021

HAL is a multi-disciplinary open access archive for the deposit and dissemination of scientific research documents, whether they are published or not. The documents may come from teaching and research institutions in France or abroad, or from public or private research centers.
L'archive ouverte pluridisciplinaire HAL, est destinée au dépôt et à la diffusion de documents scientifiques de niveau recherche, publiés ou non, émanant des établissements d'enseignement et de recherche français ou étrangers, des laboratoires publics ou privés. 


\title{
Soil reinforcement with geosynthetic for localized subsidence problems: Experimental and analytical analysis
}

\author{
Mouhamad Hassoun ${ }^{1}$, Pascal Villard ${ }^{2}$, Marwan Al Heib ${ }^{3}$, and Fabrice Emeriault ${ }^{4}$ \\ ${ }^{1} \mathrm{PhD}$, INERIS, Parc Technologique ALATA, BP 2,60550 Verneuil-en-Halatte, France. \\ mouhamad.hassoun@ineris.fr \\ ${ }^{2}$ Professor, Univ. Grenoble Alpes, 3SR, CNRS UMR 5521, Domaine Universitaire, BP 53, 38041 \\ Grenoble Cedex 09, France. pascal.villard@3sr-grenoble.fr \\ ${ }^{3}$ HDR, INERIS, Ecole des Mines, Campus ARTEM, 54042 Nancy Cedex, France. \\ marwan.alheib@ineris.fr \\ ${ }^{4}$ Professor, Univ. Grenoble Alpes, 3SR, CNRS UMR 5521, Domaine Universitaire, BP 53, 38041 \\ Grenoble Cedex 09, France. fabrice.emeriault@3sr-grenoble.fr
}

\begin{abstract}
This study focuses on the evaluation of the load transfer mechanism and the determination of the shape of the load distribution transmitted to the geosynthetic layer when a cavity appears under granular and cohesive backfills. Trapdoor experimental technique with high speed acquisition of digital images and continuous monitoring of load and displacements were used for this purpose. Testing different soil types, it has been demonstrated that an approximate parabolic or inverted triangular load distribution seems acceptable for granular soil layer, whereas for cohesive backfill the load distribution could be approximately represented by two concentrated forces near the edges of the cavity. In both cases, an important overload on the soil surface could change the shape of load acting on the geosynthetic sheet. Experimental results are then approached by Terzaghi's formulation with an appropriate shape of load distribution and a convenient value of the earth pressure coefficient. Finally, recommendations are proposed to promote a better design of such
\end{abstract}


reinforcement structures.

Key words: Sinkhole, geosynthetic, design, trapdoor, granular and cohesive soils

\section{INTRODUCTION}

Localized collapse (sinkhole) can occur in karstic regions, former mining areas or in zones of poor geotechnical characteristics. Ground subsidence represents a significant geo-hazard not only to infrastructures but to residential properties as well (Al Heib et al., 2013). The geosynthetic reinforcement (GR) is an economic and effective solution to reduce the total and differential settlement problems when limited construction time is available and small deformation is allowable (DGGT, 2012). When a geosynthetic layer is placed on a deformable soil on which vertical loads are further applied, loads are transmitted to the geosynthetic layer relieving the subsoil unable to support them. In this case, the geosynthetic takes up the vertical loads and diffuses them in the form of tensile forces transfered by friction in the anchorage areas.

The design of such geosynthetic reinforcement layer goes through two main steps: Step (1) calculates the effective amount of the applied load on the GR layer, where a load transfer mechanism should be taken into account. Step (2) determines the maximum GR strain on the basis of the result of step (1); load distribution over GR, subsoil reaction, and GR stiffness should be known. Finally knowing the maximum GR strain and the GR stiffness gives the mobilized tensile force which should be smaller than the long-term GR tensile strength.

Several methods are available to design a GR over cavities (RAFAEL, 1997; Briançon and Villard, 2008; BS8006, 2010; DGGT, 2012), all with their own hypotheses for the design calculation. The difficulty is that these models give results that largely differ, and may lead to more expensive design than necessary (Huckert et al., 2016).

The objectives of the experimental study are to determine with precision the load transfer mechanism that develop within shallow granular and cohesive backfills subjected to localized subsidence and the corresponding load distribution on the GR layer and further to validate an appropriate analytical design model with these results. 


\section{LITERATURE REVIEW}

A localized loss (sinkhole) of ground support generates a local redistribution of stress and deformation within the soil mass, often known as arching. Soil arching is defined by Mc Nulty (1965) as the ability of a material to transfer loads from one location to another in response to a relative displacement between the locations. The pioneer work on this subject was performed by Marston and Anderson (1913) and Terzaghi (1943) who reproduced this effect with a trapdoor test by imposing a localized displacement to a horizontal rigid support. The classical experimental setup to investigate load transfer in the trapdoor test has been reviewed by many authors, (Vardoulakis et al., 1981; Evans, 1983; Stone and Muir Wood, 1992; Costa et al., 2009; Chevalier, 2008; Iglesia et al., 2014; Cox, 2014) under normal gravity as well as under an increased gravitational field using a centrifuge facility. All researchers observe that the movement of an active trapdoor causes an instantaneous reduction of soil stresses (initially geostatic) above the trapdoor and an increase of stresses in the adjacent soil mass, but they seldom agree on the value of this reduction. Terzaghi (1943) assumed that the lateral load transfer occurs through shear stresses along vertical planes going from the edges of the trapdoor to the ground surface. Iglesia et al. (1999) investigated the load transfer effect using a trapdoor apparatus in a geotechnical centrifuge and postulated the loading profile on the trapdoor as well as the arching evolution.

While many researchers have chosen one shape to represent the zone affected by the subsoil collapse (Guido et al., 1987; Carlsson, 1987; Hewlett and Randolph, 1988; Han and Gabr, 2002), centrifuge tests performed by Iglesia et al. (1999) suggested that the volume of soil supposed to act on the area of subsoil of poor mechanical characteristic goes through a series of stages between curved, triangular and prismatic shape before coming to rest or collapse. Stone and Wood (1992) and Chevalier (2008) have reported under shallow conditions $(H / B \leq 2)$ a mechanism similar to that given by Iglesia et al. (1999). The mechanism reported for shallow backfills observed by Stone and Wood (1992) and Chevalier (2008) involves the development of multiple (internal and external) failure surfaces in the region above the trapdoor, with soil directly above the trapdoor remaining essentially rigid. This failure mechanism differs significantly from those observed by Costa et al. 
(2009) under deep conditions, where the failure surface is observed involving a single and well defined internal failure surface which becomes gradually more inclined to the vertical when the downward movement of the trapdoor increases. This sequence of arching evolution explains the variation in stress acting on the trapdoor.

There are several other recent studies focused on the numerical modeling of the load transfer effect (Le Hello and Villard, 2009; Chevalier, 2008; Han et al., 2011; Pardo and Sáez, 2014; Huang et al., 2015; Villard et al., 2016; Rui et al., 2016). Rui et al. (2016) observed numerically three soil evolution patterns in multiple trapdoor systems. The focus of previous studies on active trapdoor has been mainly limited to the failure mechanism, arching evolution within soil mass and the interpretation of the loading curve on the trapdoor, where no geosynthetic reinforcement has been used or fully studied. Based on true scale experiments (Villard and Briançon, 2008), numerical studies of the behavior of a reinforced thin granular layer (ratio between the thickness of the embankment and the width of the cavity $H / B=0.25$ ) were performed (Villard et al., 2009; Yan and Bathurst, 2017). Comparisons were mainly based on the load transfer mechanisms, the surface settlements and the tensile strains of the geosynthetic. The DEM-FEM model (Villard et al., 2009) provides additional results that cannot be obtained during the experiment, as for example the strain pattern within the granular layer under large deformations. The existing conclusions concern the granular material case (cohesionless frictional backfills), and cannot be easily used for a cohesive soil layer. Huckert et al. (2016) have experimentally simulated sinkholes under both granular and cohesive soil layers reinforced with geosynthetic. Different collapse mechanisms have been underlined for granular and cohesive backfills. A particular load transfer mechanism has been proposed as well as the corresponding deflected shape of the geosynthetic layer above void in the case of cohesive soil, while literature analytical assumptions inspired from the granular backfill case have been shown unsuitable for the design of the geosynthetic layer. Therefore, researches investigating such behavior are strongly needed.

\section{TRAPDOOR APPARATUS AND MODEL TEST}




\section{Trapdoor apparatus}

As shown in Fig.1, the test set-up consists in a rigid base, a subsidence simulator and a box. The box is $1000 \mathrm{~mm}$ in length, $400 \mathrm{~mm}$ in width, and $200 \mathrm{~mm}$ in height. Only shallow embankments are considered in this study. The front wall of the box consists in a transparent Plexiglas plate used to enable visualization of the models during testing, while the other sides were made of wood. The subsidence simulator (Trapdoor) has a fixed width $B=200 \mathrm{~mm}$ and is located in the bottom of the box in its center. The trapdoor can move downwards to $50 \mathrm{~mm}$ with a speed of nearly $0.016 \mathrm{~mm} / \mathrm{s}$. This causes the creation of a void within the soil mass with a predetermined vertical displacement $\delta$ measured with linear variable displacement transducer (LVDT). The displacement transducer has an accuracy of $0.05 \mathrm{~mm}$. The vertical effort, called $(\mathrm{P})$, applied by the soil material on the trapdoor was measured using a load cell with $1 N$ of precision. In order to limit the wall boundary effects on the measurements, $(\mathrm{P})$ is measured in the central part of the trapdoor of $200 \mathrm{~mm} \times 200 \mathrm{~mm}$. The corresponding average vertical stress $(p)$ is deduced from $(\mathrm{P})$ and the dimensions of the central part of the trapdoor. Test model is designed to reproduce a prototype scaled by factor $n=10$ on lengths, where the real state of stress is not respected. This type of scaling neglects the influence of the modulus of the backfilled soil and of gravity on the backfill behavior. Rigorous scaling factors of the proposed tests at $1 \mathrm{~g}$ proved difficult to ascertain (Zhu et al., 2012). Consequently, it will be difficult in this context to make quantitative interpretation of the experimental results. Scaling factors of the main parameters of the model test are resumed in Table 1. The use of a flexible rubber membrane for the reinforcement at the base of the soil layer does not allow measuring the total load acting on the trapdoor. Therefore, an original specific process using photogrammetry technique has been used to determine the reinforcement strain and deduce the vertical load distribution acting on the membrane all over the void.

\section{Soil and reinforcement properties}

The considered soil layers are either made of a granular (cohesionless) material or a cohesive sandy-clay. The shear strength parameters of these geomaterials have been obtained from conventional triaxial compression tests (Table 2). In order to obtain the stress levels during the triaxial tests 
comparable to those observed in the trapdoor tests, the confinement stress was relatively low with $\sigma_{r}=5,10,15 \mathrm{kPa}$. The gravel of a specific gravity $\gamma=15.2 \mathrm{kN} / \mathrm{m}^{3}$ has a maximum and minimum particle size $d_{\max }$ and $d_{\min }$ of $12.5 \mathrm{~mm}$ and $5 \mathrm{~mm}$ respectively, a coefficient of uniformity $C_{u}$ of 1.61 , a peak and residual friction angle $\phi_{\text {peak }}$, and $\phi_{\text {res }}$ of $53.6^{\circ}$ and $40.1^{\circ}$ respectively. The sandy-clay material has a dry unit density $\gamma_{d}=13.8 \mathrm{kN} / \mathrm{m}^{3}$, a friction angle $\phi=35^{\circ}$, a $15 \%$ moisture content and a cohesion $C=5.5 \mathrm{kPa}$. The liquid limit $W_{L}$, plastic limit $W_{P}$ and plasticity index $I_{P}$ are respectively $37 ; 20$ and $17 \%$. The sandy-clay soil grains have a maximum diameter of $7 \mathrm{~mm}$ where $97.8 \%$ of them are $<2 \mathrm{~mm}, 67.7 \%$ are $<80 \mu \mathrm{m}$ and $23.6 \%$ are $<2 \mu \mathrm{m}$. A $2 \mathrm{~mm}$-thick flexible rubber membrane has been used to represent the geosynthetic reinforcement in order to respect the condition of similarity and to allow measuring the tensile strain using a photogrammetry technique. The tensile behaviour of the membrane has been characterized in tensile tests on $20 \pm 1 \mathrm{~mm}$ wide specimens. Load - extension curves show a non linear elastic behavior of the tested membrane, the variation of the axial stiffness $J$ defined per unit length of the geosynthetic layer in the range of strain measured in trapdoor tests is given in Fig.2. Considering the scaling factor of $n=10$ a value of the tensile stiffness equal to $20 \mathrm{kN} / \mathrm{m}$ in the small model corresponds to a value of $2000 \mathrm{kN} / \mathrm{m}$ in the full-scale case which is a classical value used in reinforcement applications.

\section{Test program}

The model tests using gravel have been carried out for three different overburden heights, i.e., $H / B=0.25,0.5$ and 0.75 respectively. Tests $1-3$ have been carried out without GR, however in Tests 4-6 the GR is used to conclude on the effect of the GR on the load transfer mechanism and backfill soil behavior. Only one GR layer with a unique tensile stiffness is tested here. A soil layer with $H / B=0.25$ has been tested for the sandy-clay layerin tests 7-8. This study mainly deals with the behavior of shallow backfill over cavity where $(H / B \leq 0.75)$. The test program is listed in Table 3.

We note that each presented test has been repeated three times, 24 tests have been carried out in total, all results are similar and will therefore be given in the format of the mean experimental value \pm the maximum average spread. 
In Tests 4-6 and 8, the soil surface is loaded successively by two linear uniform loads ( $Q_{1}$ and $Q_{2}$ ) placed above the middle of the trapdoor using steel bars of $25 \pm 1 \mathrm{~mm}$ in width, $50 \pm 1 \mathrm{~mm}$ in height and $400 \mathrm{~mm}$ in length. Each steel bar $Q_{1}$ and $Q_{2}$ has a total weight of $23 \mathrm{~N}$. These loads have been applied to investigate the reinforcement response against such surface loading, and purposely to produce the collapse of the cohesive backfill in Tests 7-8.

\section{Photogrammetry}

A key requirement of the research is to provide accurate measurements of soil movement and GR displacements in ordre to determine accurately the vertical load distribution acting on the GR. Digital images have been captured remotely via a PC mounted next to the model test using 15 Megapixels cameras. Images have been processed using the image analysis software VIC 2D. Full field two-dimensional displacement and strain data are thus provided for both the soil layer and the GR sheet. Determining the strain distribution at different points on the GR sheet over cavity is a big issue since it is further used to calculate the tension force induced in the GR and also the shape and intensity of the load transmitted to the GR due to the cavity appearance as explained in the next section. The soil layer is considered as having naturally a large enough variation in texture to allow an accurate tracking from one image to another. In addition, a speckle pattern has been projected on the edge of the GR using spray cans to enable the use of digital image correlation technique $(D I C)$ on this thin structure. The GR is sufficiently separated from the box boundaries to avoid any interaction that could disturb the results.

Note that in order to effectively filter out scatter in experimental measurements, displacement curves have been smoothed. Smoothness of both vertical and horizontal measurements is essential in order to obtain clearer estimations for strain and load distribution. Smoothing was applied using an interpolation spline, which fits a smooth curve exactly through the given data points. The used spline is defined piecewise by polynomials, using this smoothing theory avoids Runge's phenomenon and provides the best smoothing curve (Birkhoff and de Boor (1965)). The 1standard deviation confidence in the match at a correlated point changes from 0.0125 to 0.115 pixel $(1$ pixel $=0.105948 \mathrm{~mm})$. A 0 value indicates a perfect match; higher numbers indicate a 
noise.

\section{GR response: Exploitation method}

The GR strain is calculated successively between every two points $i$ and $i+1$ of GR layer all along the trapdoor by comparing their initial coordinates noted $\left(x_{i}, y_{i}\right)$ and $\left(x_{i+1}, y_{i+1}\right)$ and their corresponding final positions after the trapdoor has moved down noted $\left(x_{i}^{\prime}, y_{i}^{\prime}\right)$ and $\left(x_{i+1}^{\prime}, y_{i+1}^{\prime}\right)$ respectively (Fig.3). The strain between points $i$ and $i+1$ is obtained, considering no change in curvature between the two points. The strain $\varepsilon_{i, i+1}$ between points $i$ and $i+1$ is obtained by:

$$
\varepsilon_{i, i+1}=\varepsilon_{j}=\sqrt{\frac{\left(\left(x_{i+1}^{\prime}-x_{i}^{\prime}\right)^{2}+\left(y_{i+1}^{\prime}-y_{i}^{\prime}\right)^{2}\right)}{\left(\left(x_{i+1}-x_{i}\right)^{2}+\left(y_{i+1}-y_{i}\right)^{2}\right)}}-1
$$

The induced tensile force defined per unit width of the geosynthetic is then deduced by:

$$
T_{j}=J(\varepsilon) \varepsilon_{j}
$$

Knowing final positions of points on the GR, the GR inclination with respect to the horizontal direction could be determined at any point along the GR layer as following:

$$
\tan \alpha_{j}=\left(y_{i+1}^{\prime}-y_{i}^{\prime}\right) /\left(x_{i+1}^{\prime}-x_{i}^{\prime}\right)
$$

Using the induced tensile force and the GR sheet inclination in Eq. 2 and Eq. 3, the vertical component of the tensile force can be calculated with:

$$
T_{v, j}=T_{j} \sin \alpha_{j}
$$

Finally, the vertical load acting at any point of the GR layer over the cavity is obtained considering the vertical equilibrium of a part of the GR of length $\Delta x$ (Fig.3):

$$
q_{j, j+1}=q_{k}=\frac{\Delta T_{v}}{\Delta x}=\frac{T_{v, j+1}-T_{v, j}}{x_{j+1}-x_{j}}
$$


Where $q_{k}$ expressed in $k N / m^{2}$ is the vertical surface load between two points $\mathrm{j}$ and $\mathrm{j}+1$ on the GR over the cavity, whose abscissa difference is noted $\Delta x$, and $\Delta T_{v}$ is the associated variation in vertical component of the tensile force defined by meter width. It should be noted that shear forces along GR over the cavity originating from soil / geotextile interaction are not taken into account in the derivation of Eq.5.

\section{Experimental validation of the procedure for the load distribution determination}

In this section, we report on experiments designed to test the effectiveness of the exploitation procedure presented above to deduce the distribution of load transmitted on the GR over cavity. The presented experimental results aim to secure that the exploitation method is satisfying with respect to representativeness, reproducibility and repeatability. Validation experiments consist in the loading of the GR layer with a cylindrical metal tube with a weight of $22 \mathrm{~N}$ and a diameter equal to $50 \mathrm{~mm}$ spreading over the model box width $(400 \mathrm{~mm})$ with a gap of $2 \mathrm{~mm}$. Three tests (Tests (a), (b) and (c)) have been carried out in the same conditions and compared in terms of strain distributions. No soil mass is used in these tests, the GR layer is stabilized with a 300N metallic plate on each anchorage side next to the trapdoor edges. The plates have the same dimensions as the anchorage zones and their weight is supposed uniformly distributed over the whole anchorage area (400mm x 400mm) (Fig.4).

Strain distributions of GR for three identical tests are presented in Fig.5a. Experimental values show a good convergence with almost a linear strain distribution over the trapdoor. These results are close to the theoretical estimation $(\varepsilon=1.25 \%)$, obtained from the analytical resolution of the GR sheet equilibrium under cylindrical tube loading assuming no friction between the flexible rubber membrane and the tube, a constant value of the GR tensile strain over the void and an horizontal displacement of the GR in the anchorage area $(0.28 \mathrm{~mm}$ as experimentally observed). Strain distribution is slightly antisymmetric over the cavity, this could be explained by the fact that the anchorage conditions were not perfectily identical on both sides of the anchorage zones, and that the GR layer was not fully mobilized. Fig.5b shows the vertical tension curve, obtained from the average smoothed strain distribution in Fig.5a applying Eq.4. An approximately constant value 
of $T_{v, j}$ is observed between the two edges of the cavity.

If we note $\mathrm{A}$ and $\mathrm{B}$ the points of the GR at the edge of the cavity, we obtain $T_{v, A}=30.3 \mathrm{~N} / \mathrm{m}$ and $T_{v, B}=24.7 \mathrm{~N} / \mathrm{m}$ ( Fig.5b). The weight of the cylindrical tube could be estimated using: $Q_{2 T v}=0.4\left(T_{v, A}+T_{v, B}\right)=22 N$ which is equal to the real weight of the cylinder.

Using Eq.5, the shape of load distribution transmitted to the GR can be determined as shown in Fig.5c. Transmitted load reaches a maximum at the tube/GR interface, then drops suddenly to nearly zero along the GR over the rest of the trapdoor. The weight of the cylinder could be also calculated by the integration of the load distribution curve over cavity saying: $Q_{\text {Int }}=\int_{x=-100}^{x=+100} \int_{z=0}^{z=400} q_{k} d x d z=$ $22.56 N$. The integration of the load distribution curve over cavity seems also satisfying to estimate the real applied load on the GR. $Q_{2 T v}$ and $Q_{\text {Int }}$ are relatively equivalent.

The exploitation procedure is therefore judged reliable and fulfilling the intended purposes. All the results presented thereafter are based on the average strain between repeated tests.

\section{UNREINFORCED GRANULAR SOIL: TESTS 1-3}

\section{Loading response - Arching theories vs. experimental results}

Fig.6 shows the trapdoor average vertical stress $p$ normalized by the geostatic stress $p_{0}=\gamma H$, against the trapdoor displacement $\delta$ normalized by the trapdoor width $B$.

Similar trends are obtained in Tests 1-3 with a good general agreement with Chevalier (2008) and Iglesia et al. (2014) findings. As the trapdoor is lowered, the stress on the trapdoor drops rather abruptly to reach a minimum value generating maximum arching and then gradually increases (approximately linearly) before being roughly constant until the trapdoor cannot move down any further. The most significant difference between Tests 1-3 is the stress reduction amount and the ultimate recovered stress. The displacement corresponding to the minimum load on the trapdoor tends to fall within a wider range $(\delta / B \approx 1.35 \%)$ for all tests. This range is in full agreement with results reported by Chevalier (2008). Initial stress is reduced to $68 \%, 55 \%$ and $35 \%$ of $p_{0}$ for respectively $H / B=0.25,0.5$ and 0.75 due to load transfer effect. A higher reduction is observed for thicker soil layers. Unlike deep soil layers, loading curves obtained for both small values of $H / B$ and large trapddor displacement $\delta$, show different minimum absolute stress $(p)$, which increases 
with soil depth. This could be explained by the fact that the load transfer action is not identical and prevented from effectively forming in Tests 1-3, i.e., arching cannot be fully sustained in regular manner when the overburden is relatively shallow and the ratio of soil height to trapdoor width $(H / B \leq 0.75)$ is lower than the lower limit $(1.5 \leq H / B \leq 2)$ estimated by Terzaghi (1943) to have a stable arching action.

In addition, for the ultimate state reached for large trapdoor displacement $\delta$ (i.e. $\delta / B=100 \%$ ), Test-1 with $H / B=0.25$ shows that the initial geostatic pressure is approximately fully recovered, whereas in Tests 2 and 3 with $H / B=0.5$ and 0.75 a reduction of $13 \%$ and $20 \%$ respectively is still observed.

In this section, more attention is payed to the estimation of the maximum stress reduction generated by load transfer mechanisms. A summary of the equations proposed in previously published arching theories to estimate minimum and ultimate loading caused by active trapdoor movements is provided in Table 4.

Among the minimum load expressions proposed in the literature, Engesser (1882), Iglesia et al. (2014), Bierbaumer (1913), Evans (1983) and Guido et al. (1987) are chosen for general comparison. Horizontal lines in Fig.6 represent the maximum stress reduction estimations of different analytical equations for Test-3.

Engesser (1882) formulation that adopts an initial parabolic shape of the collapsed backfill zone at the maximum load transfer provides an estimation close to experimental results. Modifications on Engesser (1882) formulation proposed by Iglesia at al. (2014) gives the best estimation of the maximum load transfer mechanism in the case of unreinforced granular soils.

\section{Vertical displacement analysis}

Fig.7 shows the contours of vertica granular soil displacements $\left(S_{v}\right)$, for trapdoor displacements equal to (a) $0.75 \%$, (b) $1.65 \%$, (c) $3.5 \%$ and (d) $9.5 \%$ of the trapdoor width $B$. The general pattern of displacements is shown to change with $\delta$. Loading curve response and vertical displacement fields illustrate the three main stages of the behavior of a shallow granular backfill.

Initial or maximum load transfer: as soon as the trapdoor is moved, the soil grains come 
immediately into contact with each other and allow the formation of a force (arch) path oriented toward stable areas. The moving area is located above the cavity in the shape of an inverted parabola (Fig.7a). At this point, the maximum load transfer mechanism is obtained. Chevalier (2008) reported that this stage corresponds to soil decompaction.

Loading recovery: this stage is a transition from the maximum load transfer (minimum loading) to the ultimate state. The moving zone of soil is larger and reaches the soil surface, the initial parabolic displacement pattern cannot be sustained and evolves towards an approximately trapezoidal one (Fig.7b). Thus, Fig.6 shows that stress variation in this stage is almost linear, the slope represents the way the load transfer decreases progressively as trapdoor move down. Fig.6 shows that load recovery index decreases with the ratio of the height of the soil layer to the trapdoor width. This can be explained by the fact that arching is more efficient with thicker backfills.

Ultimate state: as the trapdoor continues to move. the whole height of the backfill above the trapdoor is affected by the displacement of the latter, the arch pattern doesn't exist anymore and two vertical shear bands develop at the edge of the trapdoor instead (Fig.7d).

The soil immediately above the trapdoor is moving at the same rate as the trapdoor displacement $\delta$. On the opposite, the ratio of the settlement at the soil surface to the trapdoor displacement $\delta$ is significantly lower than 1 , indicating the zone of soil above the trapdoor is dilating.

\section{REINFORCED GRANULAR SOIL: TESTS 4-6}

For these tests, due to the presence of the GR, neither subsidence displacement $\delta$ nor the applied stresses on trapdoor have been measured.

The mechanism observed for the three backfill heights $(H / B=0.25,0.5$ and 0.75$)$ used in the previous section have been reconsidered this time with a geosynthetic reinforcement layer. The same GR layer has been used in the three tests. Direct measurements of the displacement have been performed on both granular soil layer and along the GR layer using DIC technique. The influence of GR on the displacement field in the overlying soil layer is qualified, and analytical estimations of the load acting on the GR layer proposed in the literature are compared to the experimental results. Placed directly on the rigid base of the trapdoor model, the GR layer has been anchored on each 
side over $400 \mathrm{~mm}$ from the trapdoor edge under only the weight of the soil backfill. Data acquisition stops when the trapdoor loses any contact with the GR layer.

\section{Vertical displacement analysis}

Vertical settlements are significantly smaller than those obtained in the unreinforced soil case not only at soil surface but also at different depths in the backfill. For Test 6, the maximum vertical displacement at soil surface appear in Fig. 8 as reduced 35\% compared to the unreinforced backfill in Test 3 for the same final trapdoor displacement (9.5\% of $B$ ) at which the GR takes off from the trapdoor. This observation is explained by the mobilization of the GR layer that prevents the soil above the edges of the cavity to move downwards and thus reduces its deformation and expansion.

\section{GR behavior: Strain and load distribution}

Tensile strain and load distributions along the GR layer determined by photogrammetry analysis are presented in this section. The results of Tests 5 and 6 showed similar trends, therefore tensile strain and load distributions are given for only Tests 4 and 6. For Tests 5 and 6 (under backfill weight and overloads), the tensile strain of the GR at the edges of the trapdoor are generally larger than those obtained at midspan, while the tensile strain variation of the GR in the central part of the trapdoor is quite small even after surface loading (Fig.9). The reason of the higher strains in GR at the dges of the trapdoor than in the adjacent zone is due to the vertical stress concentration at the edge of the trapdoor shown hereafter, which is similar to the abrupt-increase strain in geosynthetic at the edges of piles firstly discovered by Han and Gabr (2002). Obtained strain patterns, above the cavity and in the anchorage zones, are similar to the analytical, numerical and full-scale experiment results founded by Villard and Briançon (2008), Villard et al. (2009). On the opposite, the GR tensile strain in Test 4 is approximately constant over the length of the trapdoor for unloaded case (Fig.10). This phenomenon is explained by the large amount of sliding of the GR layer in the anchorage areas where the confinement stress is very low and unable to effectively counterbalance the load transmitted to the GR on top of the trapdoor. The tensile strain in the GR reaches a maximum in the center of the trapdoor and decreases gradually towards the trapdoor edges, the load transfer mechanisms are thus strongly affected. 
Accordingly, Fig. 11 concludes that the load distribution in the GR over the trapdoor determined by the established experimental analysis procedure approaches for Tests 5 and 6 an inverse triangular distribution. Arching mechanism effect is well observed. Contrary to RAFAEL (1997), BS8006 (2010) and EBGEO (2011) hypothesis, a non uniform distribution was shown. The obtained shape of the load distribution meets experimental and numerical conclusions of Villard et al. (2016) and Han and Gabr (2002).

Further loading of the soil surface with $Q_{1}$ and $Q_{2}$, the shape of load distribution in Test 5 does not significantly change, a small increase in the stress in the center and at the trapdoor edges is observed. The backfill in Test 6 appears to be less influenced by surface loading. On the other hand, for unreinforced Test 4 the load distribution does not reflect an effective load transfer mechanism. Loading the soil surface drastically changes the shape of the load distribution acting on the GR, with a concentration of stress near the center of the trapdoor (Fig.12).

The stress reduction ratio $(S R R)$ is defined as the ratio of total load $Q$ transmitted to the GR above the trapdoor and calculated experimentaly with $Q=0.4\left(T_{v, A}+T_{v, B}\right)$, to the initial average geostatic stress applied by the backfill weight $(E)$ plus eventual surface loads $Q_{1}$ and $Q_{2}$. The lower the value of $S R R$, the greater the arching effect, a $S R R$ of 1.0 implies no arching.

$$
S R R=Q /\left(E+Q_{1}+Q_{2}\right)
$$

As expected, Fig.13 shows that $S R R$ decreases with an increasing backfill height, a larger soil arching effect being underlined for thicker soil layers. Stress reduction ratio is approximately $70 \%, 45 \%$ and $35 \%$ in unloaded Tests 4, 5 and 6 respectively. Arching in Test 5 is shown to be maintained after $Q_{1}$ was applied. Arching effect is even more relevant in Test 6, where a constant $S R R$ is calculated for all loading cases.

For Test 4, the large displacement of the granular layer due to the sliding of the GR in the anchorage areas, combined with the frictional mechanism at the interface between GR and the granular particles, lead to complex load transfer mechanisms that increase with additional overloads. A remarkable point, that needs to be pointed out, is that $S R R$ values for Tests 4-6 (with reinforcement) 
are approximately equal to the maximum stress reduction ratio in unreinforced Tests 1-3 (Fig.6). This observation leads to conclude that the reinforcement layer has maintained the "maximum load transfer" stage mentioned earlier even for larger subsidence.

\section{Comparison with analytical approaches of the GR deflection and strain}

Several analytical models for the design of GR layer are available in literature. An analytical model requires two elements: an arching model that provides the stress applied on the GR layer and the shape of the load distribution on the GR above void. From these elements, the equilibrium equations can be established and the corresponding GR tensile strain and induced tension are calculated. These models generally differ in arching values and load distribution shapes. Considering the equilibrium of a differential rectangular element on trapdoor, Terzaghi (1943) estimates the ultimate vertical applied stress $\sigma_{v}$ for unloaded cohesionless backfill as follow:

$$
\sigma_{v}=q_{0}=\frac{\gamma B}{2 K \tan \phi}\left(1-\exp ^{2 K \tan \phi \frac{H}{B}}\right)
$$

Where $K$ is the ratio between the horizontal and vertical stresses $\left(K=\frac{\sigma_{h}}{\sigma_{v}}\right)$.

Terzaghi formula provides a stress estimation that depends to a large extent on the value of $K$. Various authors have used this theory but with different assigned values for $K$, which is difficult to be determined experimentally with an accurate value. The different proposed values of lateral earth pressure coefficient $K$ are shown in Table 5.

Fig.14 shows a comparison of average soil pressures acting on the GR calculated by Terzaghi formula for different $K$ expressions given in Table 5 with Tests 4-6 results. The sensitivity of Terzaghi equation (Eq.7) on different formulations of K is clearly illustrated, high disparity between different estimations of vertical stress is observed. The calculated soil pressures using $K$ proposed by Aubertin et al. (2003), and Chen et al. (2010) underestimate tests results. On the opposite, Handy (1985) and Marston \& Anderson (1913) highly over-estimate experimental measurements. Terzaghi (1943) proposition appears as a secure choice. Huckert et al. (2014) estimation of $K$ from true scale experiments approaches at best the obtained experimental results. 
The shape of the load distribution on GR layer is also of high importance. Here various geometries for the distribution of vertical stress have been tested in terms of maximum GR deflection and tensile strain. All the considered distributions have the same average stress intensity, as defined by Terzaghi in (Eq.7), with $K=1.3$ as proposed by Huckert et al. (2014). $\phi$ is assumed to be the peak friction angle of the granular material. The use of $\phi_{\text {peak }}$ is based on the results obtained in the previous section where a maximum arching effect was proved at the end of Tests 4-6. Only the cases without loading at the soil surface are considered in this section. Analytical developments proposed by Huckert et al. (2016) and Villard et al. (2016) have been used for comparison with the experimental results. The main assumptions of the proposed analytical model are a non uniform load on the GR over the cavity, the sliding and the friction of the GR in the anchorage areas on each side of the cavity.

Parabolic and inverted triangular load distributions are proposed to match the experimental results. Equilibrium equations for the corresponding load distribution are given in Table 6. The effect of both null and low (denoted NZ for Non-Zero) values of the stress at the center of the trapdoor has also been studied. For the NZ cases, the vertical stress at the trapdoor center is assumed to be equal to $0.22 \mathrm{kPa}$ as shown in Fig.12 and Fig.11.

Importance of GR displacement at the edge of the cavity $\left(U_{A}\right)$ on its maximum deflection and tensile strain is also highlighted by using experimental values of $U_{A}\left(U_{A}=1.34,0.82,0.77 \mathrm{~mm}\right)$ for Tests 4-6 respectively. Comparison between analytical and experimental results for Tests 4-6 in terms of maximum GR deflection and strain is presented in Table 7.

The comparison shows that NZ parabolic or inverted triangular load distributions are required to estimate accurately the maximum deflection and tensile strain in the GR. This conclusion is valid for granular cohesionless backfills and considering an adequate value of $K=1.3$ as proposed by Huckert et al. (2014) and the displacements of the GR layer at the edges of the cavity as recommended by Villard and Briançon (2008) in such case.

\section{TESTS WITH A COHESIVE SOIL BACKFILL TESTS 7-8}


Few experimental tests have been carried out so far to simulate the sinkhole opening under a cohesive soil layer. The mobilized failure mechanisms in such cohesive soil under localized sinkhole being still not clearly identified, the main objectives of this section are a better understanding and description of the total transferred load, of the shape of the load distribution on the GR layer and of the GR behavior in anchorage zones.

In Test 7, an unreinforced layer of manually compacted cohesive soil with $H / B=0.25$ has been observed bridging the trapdoor cavity with very small maximum deflection $(0.35 \% \mathrm{~B})$ after the trapdoor was moved down. The cohesive backfill behaves as a slab with small deflection at its center. No cracks appeared neither at the edges nor at the center of the cavity. In this case, the soil layer ensures its own stability thanks only to its cohesion (Fig.15a). Similarly to reinforced granular Tests 4-6, when the trapdoor reaches its lower position, loads $Q_{1}$ and $Q_{2}$ have been applied on the ground surface to cause the backfill failure. $Q_{1}$ appears as the minimum load required for the collapse of the unreinforced soil layer associated with the development of several relatively big blocks on the trapdoor as observed in Fig.15b.

The previous collapse mechanism has not been fully observed when the cohesive layer is reinforced (Test 8). Firstly, the cohesive soil layer lost instantaneously the contact with the trapdoor and the GR layer deflects due to its own specific weight, the slab behavior is the same as in the unreinforced case. Loading the soil layer, a large volume of cohesive soil falls principally in one block on the GR. Approximately the same overload $\left(Q_{1}\right)$ has been required to cause the failure as for the unreinforced backfill, no influence of the GR is shown at this stage. The main fallen block of cohesive soil has a characteristic geometry (trapezoidal one), limited by major cracks propagating from the edges of the trapdoor up to the area close to the loaded surface (Fig.16a). Increasing the surface load to $Q_{2}$, cracks within the soil layer continue to develop with greater thickness and the GR layer is more curved at the trapdoor centre under the block of collapsed soil (Fig.16b).

The speckle pattern projected on the GR layer allows to determine the profiles of horizontal and vertical displacement after the rupture of the cohesive soil layer and to deduce therefrom the tensile strain distribution in the GR layer using (Eq.1). 
It can be seen that tensile strain distribution in GR shows a constant value above the trapdoor under $Q_{1}$ and a slight variation under $Q_{2}$ (Fig.17).

Applying the same procedure as in the granular case, after calculation of different tension components with the corresponding GR inclination, the vertical stress $q_{k}$ acting at all points of the GR layer is obtained using the relation with vertical component of the tension $T_{v}$ in (Eq.5). The stress distributions obtained after the collapse of the cohesive soil layer due to loading $Q_{1}$ and $Q_{2}$ are presented in (Fig.18).

For the two loading phases, a high concentration of stress is observed near the edges of the cavity due to the block collapse mechanism. On the other hand, the stress is very low in the central part for loading with $Q_{1}$ but more important under $Q_{2}$. The small vertical stress value on the central part of the GR layer especially under $Q_{1}$ could explain the flat shape of the GR layer in this part (Fig.16a).

Integrating the vertical stress distributions in Fig.18, the total load transmitted to the GR for $Q_{1}$ and $Q_{2}$ loading cases is respectively $34 \mathrm{~N}$ and $60 \mathrm{~N}$, i.e. $54 \%$ and $70 \%$ of the total collapsed weight above the trapdoor (weight of the collapsed soil block + overload). These values clearly lower than $100 \%$ could be explained by the collapse mechanism, where the cohesif soil layer breaks in blocks and that the forces are transmitted from one block to another and to the GR layer only at the contact points. The soil layer does not collapse completely on the GR and the soil blocks touch the edges of the trapdoor.

The obtained collapse mechanism is very close to that proposed by Huckert et al. (2014). Huckert et al. (2014) proposed to represent its effects by a localized action (stress) applied by the collapsed block on the GR layer. The distance between the two localized force is equal to the length of the base of the collapsed soil volume.

The analytical approach proposed by Huckert (2014) assumes a collapse of the cohesive soil layer in blocks when subjected to a concentrated load at the soil surface. The principle of this model is then to transfer the weight of the collapsed soil block and the surface overload to the GR layer by means of two vertical forces $(2 P)$ defined per meter of width of the geosynthetic sheet 
(Fig.19). The collapsed block is further considered rigid, undeformable and dimensionally stable. The proposed analytical model consists in solving Eq.8 for the horizontal tension $T_{h}$.

$$
U_{A}+\left[\sqrt{1+\left(\frac{P}{T_{h}}\right)^{2}}-1\right](l-B / 2)=\frac{T_{h}}{J(\varepsilon)}\left[\left(1+\left(\frac{P}{T_{h}}\right)^{2}\right)(l-B / 2)+l\right]
$$

Huckert assumed that the length 21 between the forces representing the effect of the collapsed block could be estimated with: $2 l=(l 1+2 H \tan \phi)$ where $l 1$ is the upper base of the collapsed block that could be approximated by the overload application length (equal to $50 \mathrm{~mm}$ for $Q_{2}$ loading case). The horizontal displacement $U_{A}$ is here replaced by its experimental value $(0.51$ and $1.55 \mathrm{~mm}$ for $Q_{1}$ and $Q_{2}$ respectively).

The mechanical behavior of the GR layer, at the right of the cavity, is then given by the expressions of maximum deflection, tension and GR deformation as follow:

$$
\begin{gathered}
f=\frac{P}{T_{h}}(B / 2-l) \\
T_{\text {max }}=T_{A}=T_{B}=T_{h} \sqrt{1+\left(\frac{P}{T_{h}}\right)^{2}} \\
\varepsilon_{A}=T_{A} / J(\varepsilon) \quad \varepsilon_{B}=T_{B} / J(\varepsilon)
\end{gathered}
$$

The comparison of the analytical results obtained with Huckert's model and the experimental results for the two loading phases $Q_{1}$ and $Q_{2}$ in Test- 8 is given in Table 8, the geometrical properties of the collapsed soil block being deduced from experimental observations.

Despite its simplicity, the analytical approach proposed by Huckert (2014) describes in a reasonable way the experimental results. The strong hypotheses made on the geometry of the deformed GR layer (straight segments) and on load transfer explain the gap on the maximum tensile strain and deflection of the GR layer which presents a slight curvature in the experiment. The application of the load via two localized forces can also be questioned, in particular when the intensity of the overload applied at the soil surface becomes important compared to the weight of the collapsed soil blocks and the stress becomes larger near the centre of the cavity. 
CONCLUSION

A series of experimental tests using classical trapdoor apparatus have been carried out to investigate soil arching effect, load transfer mechanism and soil - geosynthetic reinforcement interaction due to local subsidence for both granular and cohesive backfills. A specific methodology was developed in this work based on the treatment of the experimental results obtained by photogrammetry technique (DIC) to determine the interaction forces between GR and soil.

In the case of a granular soil, the main finding is that:

- Among the different propositions of load distribution, the inverted triangular or parabolic shapes appear to be the most adapted to describe accurately the experimental results.

- An additional surface loading leads to a change in the load distribution on the GR close to the middle of the cavity in the case of small $H / B$ ratios (i.e. 0.25 in Test 4 ) whereas the shape is not modified for larger values of $H / B$.

- The GR displacement and deformation in the anchorage zones are well accounted for. The intensity of the load transfer mechanism can be approached by Terzaghi’s formulation using appropriate value for the ratio between horizontal and vertical stresses $(K=1.3)$.

- Depending of the ratio $H / B$ the load transfer coefficient $S R R$ varies from $35 \%$ to $70 \%$.

A preliminary analysis has also been proposed in the case of a cohesive soil showing that:

- The load distribution on the GR is only measured when a surface load is applied and large enough to induce the failure of the soil layer that bridges the cavity.

- The resulting block applies loads on the GR that are localized close the cavity edges.

- The measured strains and tension in the GR validate to a certain extend the analytical approach proposed by Huckert et al. (2014).

The proposed experimental procedure can be further applied for other material properties and different loading configurations and will enable to propose and validate design methods, notably in the case of a cohesive backfill. 
The following symbols are used in this paper:

$B=$ trapdoor width $(\mathrm{mm})$;

$C=$ soil cohesion $(k P a)$;

$d_{\text {max }}, d_{\text {min }}=$ soil maximum and minimum particle size respectively $(\mathrm{mm})$;

$E=$ real total weight applied on the GR above the cavity $(N)$;

$J=$ axial stiffness defined per unit length of the GR layer $(\mathrm{kN} / \mathrm{m})$;

$H=$ backfill height $(\mathrm{mm})$;

$K=$ coefficient of lateral earth pressure;

$l 1=$ upper base of the collapsed sandy-clay block $(\mathrm{mm})$.

$2 l=$ distance between the two forces $(2 \mathrm{P})(\mathrm{mm})$;

$\mathrm{P}=$ vertical effort applied by the soil material on the central part of the trapdoor $(N)$;

$p=$ average vertical stress acting on the central part of the trapdoor $(k P a)$;

$p_{0}=$ geostatic vertical stress applied on the trapdoor $(k P a)$;

$(2 P)=$ two vertical forces defined per meter of width of the GR $(\mathrm{N} / \mathrm{m})$;

$Q=$ total calculated weight transmitted to the GR above the cavity $(N)$;

$Q_{1}, Q_{2}=$ overloads at the backfill surface $(N)$;

$q_{k}=$ vertical load acting at any point $\mathrm{k}$ of the GR layer over the cavity $\left(\mathrm{kN} / \mathrm{m}^{2}\right)$;

$S_{v}=$ vertical soil displacement $(\mathrm{mm})$;

$S R R=$ stress reduction ratio;

$T_{j}=$ total tensile force defined per unit width at any point $\mathrm{j}$ of the $\mathrm{GR}(\mathrm{N} / \mathrm{m})$;

$T_{v, j}, T_{h, j}=$ vertical and horizontal components of the tensile force at any point $\mathrm{j}$ of the GR $(N / m)$;

$U_{A}=$ horizontal displacement of the GR at the edge of the cavity $(\mathrm{mm}) ;$

$W_{L}, W_{P}, I_{P}=$ liquid limit, plastic limit, plasticity index of sandy-clay soil respectively (\%);

$W=$ moisture content in soil $(\%)$;

$\left(x_{i}, y_{i}\right)=$ initial coordinates of point $\mathrm{i}$ on the GR before moving trapdoor;

$\left(x_{i}^{\prime}, y_{i}^{\prime}\right)=$ final coordinates of point $\mathrm{i}$ on the GR after the trapdoor has moved down;

$\varepsilon_{j}=$ GR tensile strain at point $\mathrm{j}(\%)$;

$\delta=$ trapdoor displacement $(\mathrm{mm})$;

$\gamma=$ specific gravity of soil $\left(k N / m^{3}\right)$;

$\gamma_{d}=$ dry unit density of soil $\left(k N / m^{3}\right)$;

$\sigma_{r}=$ confinement stress in triaxial tests $(k P a)$;

$\sigma_{v}=$ average stress on the trapdoor calculated by Terzaghi's formulationi $\left(\mathrm{kN} / \mathrm{m}^{2}\right)$;

$\phi_{\text {peak }}, \phi_{\text {res }}=$ peak and residual interna soill friction angle $\left(^{\circ}\right)$; 


\section{REFERENCES}

Al Heib, M., Emeriault, F., Caudron, M., Nghiem, L., and Hor, B. (2013). "Large-scale soilstructure physical model (1g)-assessment of structure damages." International Journal of Physical Modelling in Geotechnics., 13(4), 138-152.

Aubertin, M., Li, L., Arnoldi, S., Belem, T., Bussière, B., and Benzaazoua, M., Simon, R. (2003). "Interaction between backfill and rock mass in narrow stopes." Soil and rock America., 1, $1157-1164$.

Bierbaumer, A. (1913). “Die Dimensionierung des Tunnelmauerwerkes: Studien.” Wilhelm Engelmann., (in German, cited in Iglesia et al. (2014)).

Birkhoff, Garrett and De Boor, Carl R. (1965). "Piecewise polynomial interpolation and approximation.” In: Approximation of functions., Amsterdam: Elsevier., 164-190.

Blivet, J., Gourc, J., Villard, P., Giraud, H., Khay, M., and Morbois, A. (2002). "Design method for geosynthetic as reinforcement for embankment subjected to localized subsidence." In: Proceedings of the Seventh International Conference on Geosynthetics., France, vol. 1, pp. 341-344.

Briançon, L., and Villard, P. (2008). "Design of geosynthetic-reinforced platforms spanning localized sinkholes." Revue canadienne de géotechnique., 45(2), 196-209.

BS8006, B.S. (1995). “Code of practice for strengthened/reinforced soils and other fills.” British Standard Institution, London.

Carlsson, B. (1987). "Reinforced soil, principles for calculation. Terratema AB., Linköping (in Swedish).

Chen, R.x., Zhu, B., Chen, Y.m., and Chen, R.p. (2010). "Modified terzaghi loozening earth pressure based on theory of main stress axes rotation.” Rock and Soil Mechanics., 31(5), 1402-1406.

Chevalier, B. (2008). "Etudes expérimentale et numérique des transferts de charge dans les matériaux granulaires. application au renforcement de sols par inclusions rigides.” Ph.D. thesis, Université Joseph-Fourier-Grenoble I.

Costa, Y.D., Zornberg, J.G., Bueno, B.S., and Costa, C.L. (2009). "Failure mechanisms in sand over a deep active trapdoor.” Journal of geotechnical and geoenvironmental engineering., 135(11), 
1741-1753 (2009)

Cox, C.M. (2014). "Centrifuge modelling of the ground reaction curve in fibre-reinforced soil." Ph.D. thesis, University of Nottingham.

DGGT: Deutsche Gesellschaft für Geotechnik e.V. (2012). "Recommendations for Design and Analysis of Earth Structures Using Geosynthetic Reinforcements-EBGEO.”John Wiley \& Sons. Engesser, F. (1882). "Ueber den erdduck gegen innere stutzwande (tunnelwande)." Deutsche Bauzeitung., 16, 91-93 (in German, cited in Iglesia et al. (2014)).

Evans, C.H. (1983). "An examination of arching in granular soils.” Ph.D. thesis, Massachusetts Institute of Technology.

Guido, V., Knueppel, J., Sweeny, M. (1987). "Plate loading tests on geogrid-reinforced earth slabs." In: Geosynthetic'87 Conference., pp. 216-25.

Han, J., Bhandari, A., and Wang, F. (2011). "Dem analysis of stresses and deformations of geogridreinforced embankments over piles.” International Journal of Geomechanics., 12(4), 340-350.

Han, J., and Gabr, M. (2002). "Numerical analysis of geosynthetic-reinforced and pile-supported earth platforms over soft soil." Journal of geotechnical and geoenvironmental engineering., 128(1), 44-53.

Handy, R.L. (1985). “The arch in soil arching.” Journal of Geotechnical Engineering., 111(3), $302-318$.

Hewlett, W., and Randolph, M. (1988). "Analysis of piled embankments.” Ground engineering., pp. 12-18.

Huang, J., Le, V., Bin-Shafique, S., and Papagiannakis, A. (2015). "Experimental and numerical study of geosynthetic reinforced soil over a channel." Geotextiles and Geomembranes., 43(5), $382-392$.

Huckert, A. (2014). “Approches expérimentale et numérique du dimensionnement de renforcements géosynthétiques sur cavités et inclusions rigides." Ph.D. thesis, Grenoble (in french).

Huckert, A., Briançon, L., Villard, P., and Garcin, P. (2016). "Load transfer mechanisms in geotextile-reinforced embankments overlying voids: Experimental and analytical approaches." 
Geotextiles and Geomembranes., 44(3), 442-456.

Huckert, A., Villard, P., and Briançon, L. (2014). "Experimental and numerical approaches of the design of geosynthetic reinforcements overlying voids.” The 23rd European Young Geotechnical Engineers Conference, Barcelona : pp. 133-136.

Iglesia, G.R., Einstein, H.H., and Whitman, R.V. (1999). "Determination of vertical loading on underground structures based on an arching evolution concept.” In: Geo-Engineering for Underground Facilities., pp. 495-506.

Iglesia, G.R., Einstein, H.H., and Whitman, R.V. (2014). "Investigation of soil arching with centrifuge tests.” Journal of Geotechnical and Geoenvironmental engineering., 140(2), 04013,005.

Ladanyi, B., and Hoyaux, B. (1969). "A study of the trap-door problem in a granular mass." Canadian Geotechnical Journal., 6(1), 1-14.

Le Hello, B., and Villard, P. (2009). "Embankments reinforced by piles and geosynthetics numerical and experimental studies dealing with the transfer of load on the soil embankment." Engineering Geology., 106(1), 78-91.

Marston, A., and Anderson, A. (1913). "The theory of loads on pipes in ditches and tests of cement and clay drain tile and sewer pipe." iowa state college, engr. Exp. Sta. Bull (31).

McNulty, and J.W. (1965). "An experimental study of arching in sand.” Technical report.

Pardo, G., and Sáez, E. (2014). "Experimental and numerical study of arching soil effect in coarse sand." Computers and Geotechnics., 57, 75-84.

Rui, R., van Tol, F., Xia, X.L., van Eekelen, S., Hu, G., and Xia, Y.y. (2016). "Evolution of soil arching; 2d dem simulations." Computers and Geotechnics., 73, 199-209.

Stone, K.J., and Wood, D.M. (1992). "Effects of dilatancy and particle size observed in model tests on sand." The Japanese Geotechnical Society., 32(4), 43-57.

Terzaghi, K. (1943). “Theorical soil mechanics.” Wiley, London.

Vardoulakis, I., Graf, B., and Gudehus, G. (1984). Trap-door problem with dry sand: “A statical approach based upon model test kinematics.” International Journal for Numerical and Analytical Methods in Geomechanics., 5(1), 57-78. 
Villard, P., and Briancon, L. (2008). "Design of geosynthetic reinforcements for platforms subjected to localized sinkholes." Canadian Geotechnical Journal., 45(2), 196-209.

Villard, P., Chevalier, B., Le Hello, B., and Combe, G. (2009). “Coupling between finite and discrete element methods for the modelling of earth structures reinforced by geosynthetic." Computers and Geotechnics 36(5): 709-717.

Villard, P., Huckert, A., and Briançon, L. (2016). "Load transfer mechanisms in geotextilereinforced embankments overlying voids: Numerical approach and design." Geotextiles and Geomembranes., 44(3), 381-395.

Villard, P., Huckert, A., and Briançon, L. (2016). "Numerical contribution to the design of geosynthetic reinforced embankments above circular cavities." Journées nationales de géotechnique et de géologie de l'ingénieur (in french).

Yu, Yan and Bathurst, Richard J. (2017). "Influence of selection of soil and interface properties on numerical results of two soil-geosynthetic interaction problems." International Journal of Geomechanics., 17(6): 04016136.

Zhu, B., Gao, D., Li, J.c., and Chen, Y.m. (2012). "Model tests on interaction between soil and geosynthetics subjected to localized subsidence in landfills." Journal of Zhejiang University SCIENCE A., 13(6), 433-444. 
TABLE 1. Scaling factors of model parameters

\begin{tabular}{llll}
\hline \hline Parameter & Symbol & Unit & Scaling factor \\
\hline Length & 1 & $\mathrm{~m}$ & $1 / \mathrm{n}$ \\
Gravity & $\mathrm{g}$ & $\mathrm{m} / \mathrm{s}^{2}$ & 1 \\
Stress & $\mathrm{q}$ & $k P a$ & $1 / \mathrm{n}$ \\
Deformation & $\epsilon$ & - & 1 \\
Specific weight & $\gamma$ & $k N / m^{3}$ & 1 \\
Friction angle & $\phi$ & $\circ$ & 1 \\
Young's modulus & $\mathrm{E}$ & $\mathrm{Pa}$ & $1 / n$ \\
Poisson's ratio & $\mathrm{v}$ & - & 1 \\
Tensile stiffness of geosynthetic & $\mathrm{J}$ & $\mathrm{kN} / \mathrm{m}$ & $1 / \mathrm{n}^{2}$ \\
\hline \hline
\end{tabular}


TABLE 2. Mechanical properties of the backfill soils

\begin{tabular}{|c|c|c|c|c|c|c|c|}
\hline \multirow[t]{2}{*}{ Soil } & \multicolumn{4}{|c|}{ Shear test } & \multicolumn{3}{|c|}{ Grading characteristics } \\
\hline & $\gamma_{d}\left(k N / m^{3}\right)$ & $w(\%)$ & $\phi_{\text {pic }} / \phi_{\text {res }}\left({ }^{\circ}\right)$ & $C(k P a)$ & $d_{\max }(m m)$ & $d_{\min }(m m)$ & $C_{u}$ \\
\hline Gravel & 15.2 & - & $53.6 / 40.1$ & 0 & 12.5 & 5 & 1.61 \\
\hline Sandy-Clay & 13.8 & 15 & 35 & 5.5 & 2 & $<0.002$ & - \\
\hline
\end{tabular}


TABLE 3. Test program

\begin{tabular}{llll}
\hline \hline Backfill material & Test & H/B & Description \\
\hline \multirow{4}{*}{ Gravel } & 1 & 0.25 & Unreinforced \\
& 2 & 0.5 & Unreinforced \\
& 3 & 0.75 & Unreinforced \\
& 4 & 0.25 & Reinforced \\
& 5 & 0.5 & Reinforced \\
& 6 & 0.75 & Reinforced \\
\hline \multirow{2}{*}{ Sandy-Clay } & 7 & 0.25 & Unreinforced \\
& 8 & 0.25 & Reinforced \\
\hline \hline
\end{tabular}


TABLE 4. Derived expressions for the calculation of the stress reduction on an underground structure caused by arching

\begin{tabular}{ll}
\hline \hline Reference & Equation \\
\hline \multicolumn{1}{c}{ Stress reduction at maximum arching } \\
Engesser (1882) & $\frac{p}{p_{0}}=\frac{B}{H}\left(\frac{K_{a}}{2 \tan \phi \frac{B}{H} K_{a}}+\frac{\tan \phi}{6}\right)$ \\
Bierbaumer (1913) & $\frac{p}{p_{0}}=\frac{B}{4 H \tan \phi}$ \\
Evans (1983) & $\frac{p}{p_{0}}=1-\frac{H}{B} \tan \phi$ \\
Iglesia et al. (2014) & $\frac{p}{p_{0}}=\frac{B}{H}\left(\frac{K_{E}}{2 \cot \phi+\frac{B}{H} K_{E}}+\frac{\cot \phi}{6}\right)$ \\
Guido et al. (1987) & $\frac{p}{p_{0}}=\frac{B}{4 H}$ \\
Carlson (1987) & $\frac{p}{p_{0}}=\frac{B^{2}}{4 H \tan \phi}$ \\
\hline \hline
\end{tabular}


TABLE 5. Literature expressions of $\mathrm{K}$

\begin{tabular}{ll}
\hline \hline Reference & Expression of $\mathrm{K}$ \\
\hline Marston and Anderson (1913) & $K=K_{a}=(1-\sin \phi) /(1+\sin \phi)$ \\
Terzaghi (1943) & $K=1$ \\
Handy (1985) & $K=1.06\left(\cos ^{2} \theta+K_{a} \cos ^{2} \theta\right)$ \\
Ladanyi et al. (1969) & $K=K_{E}=\left(1-\sin ^{2} \phi\right) /\left(1+\sin ^{2} \phi\right)$ \\
Aubertin et al. (2003) & $K=K_{p}=\tan ^{2} \theta$ \\
Huckert et al. (2014) & $K=1.3$ \\
Chen R.X et al. (2010) & $K=\left(\cos ^{2} \theta+K_{p} \sin ^{2} \theta\right) /\left(\sin ^{2} \theta+K_{p} \cos ^{2} \theta\right)$ \\
\hline \multicolumn{1}{c}{$\phi$ is the soil friction angle and $\theta=\pi / 4+\phi / 2$} \\
\hline \hline
\end{tabular}


TABLE 6. Equilibrium equations used in analytical models for different load distributions

\begin{tabular}{lll}
\hline \hline & Inverted triangular distribution shape & Parabolic distribution shape \\
\hline Stress equation & $q(x)=\frac{2 q_{0}}{B} x$ & $q(x)=\left(\frac{12 q_{0}}{B^{2}} x^{2}\right)$ \\
Deformed shape & $Y(x)=\frac{2 q_{0}}{3 B T_{h}}\left(x^{3}-\frac{B^{3}}{8}\right)$ & $Y(x)=\frac{q_{0}}{T_{h}}\left(\frac{x^{4}}{B^{2}}-\frac{B^{2}}{16}\right)$ \\
$\beta=\frac{d y}{d x}(x=B / 2)$ & $\beta=\frac{2 q_{0} B}{4 T_{h}}$ & $\beta=\frac{q_{0} B}{2 T_{h}}$ \\
Max. tension & $T_{\max }=\frac{2 q_{0} B}{4 \beta} \sqrt{1+\left[\frac{4 \beta x^{2}}{B^{2}}\right]^{2}}$ & $T_{\max }=\frac{q_{0} B}{2 \beta} \sqrt{1+\left[-\beta \frac{x^{3}}{B^{3}}\right]^{2}}$ \\
Max. deflection & $f=\frac{\beta B}{6}$ & $f=\frac{\beta B}{8}$ \\
\hline
\end{tabular}

$B$ : is the cavity's diameter

$T_{h}$ : is the horizontal component of the tension force in the GR

(Equations are given for positive horizontal coordinates $\mathrm{x}, x=0$ at the center of the cavity) 
TABLE 7. Analytical approach of the experimental results in Tests $4-6$ in terms of maximum GR deflection and strain

\begin{tabular}{|c|c|c|c|c|c|c|c|c|c|}
\hline & \multicolumn{4}{|c|}{ GR displacement at the edge of the cavity $U_{A}=0$} & \multicolumn{4}{|c|}{ GR displacement at the edge of the cavity $U_{A} \neq 0$} & \multirow[b]{2}{*}{$\begin{array}{c}\text { Experimental } \\
\text { results }\end{array}$} \\
\hline & Parabolic & $\begin{array}{l}\text { Inverted } \\
\text { triangular }\end{array}$ & $\begin{array}{c}\text { Parabolic } \\
\text { NZ* }\end{array}$ & $\begin{array}{c}\text { Inverted } \\
\text { triangular } \mathrm{NZ}^{*}\end{array}$ & Parabolic & $\begin{array}{l}\text { Inverted } \\
\text { triangular }\end{array}$ & $\begin{array}{c}\text { Parabolic } \\
\text { NZ* }\end{array}$ & $\begin{array}{c}\text { Inverted } \\
\text { triangular NZ* }\end{array}$ & \\
\hline \multicolumn{10}{|c|}{ Reinforced and unloaded granular embankment with $\mathrm{H} / \mathrm{B}=0.25$ (Test 4) } \\
\hline $\begin{array}{l}f_{\max } \\
(\mathrm{mm})\end{array}$ & 10.54 & 12.59 & 13.48 & 14.24 & 14.46 & 16.76 & 17.89 & 18.84 & $18.8 \pm 0.30$ \\
\hline $\begin{array}{l}\varepsilon_{\max } \\
(\%)\end{array}$ & 1.32 & 1.45 & 1.46 & 1.55 & 1.02 & 1.14 & 1.15 & 1.22 & $1.10 \pm 0.08$ \\
\hline \multicolumn{10}{|c|}{ Reinforced and unloaded granular embankment with $\mathrm{H} / \mathrm{B}=0.5$ (Test 5) } \\
\hline $\begin{array}{l}f_{\max } \\
(\mathrm{mm})\end{array}$ & 11.88 & 14.19 & 14.40 & 15.54 & 14.47 & 16.94 & 17.26 & 18.41 & $17.9 \pm 0.60$ \\
\hline $\begin{array}{l}\varepsilon_{\max } \\
(\%)\end{array}$ & 1.69 & 1.86 & 1.8 & 1.94 & 1.45 & 1.60 & 1.56 & 1.68 & $1.73 \pm 0.10$ \\
\hline \multicolumn{10}{|c|}{ Reinforced and unloaded granular embankment with $\mathrm{H} / \mathrm{B}=0.75$ (Test 6) } \\
\hline $\begin{array}{l}f_{\max } \\
(\mathrm{mm})\end{array}$ & 12.36 & 14.76 & 14.77 & 16.03 & 14.92 & 17.49 & 17.56 & 18.85 & $18.30 \pm 0.75$ \\
\hline $\begin{array}{l}\varepsilon_{\max } \\
(\%)\end{array}$ & 1.84 & 2.01 & 1.94 & 2.09 & 1.59 & 1.75 & 1.69 & 1.83 & $1.96 \pm 0.11$ \\
\hline
\end{tabular}


TABLE 8. Comparison of experimental and analytical results in Test $8(\mathrm{H} / \mathrm{B}=0.25)$

\begin{tabular}{llllllll}
\hline \hline & \multicolumn{3}{c|}{ Loading $Q_{1}$} & \multicolumn{3}{c}{ Loading $Q_{2}$} \\
\hline Results & $\mathrm{f}$ & $\varepsilon_{A}, \varepsilon_{B}$ & $T_{A}, T_{B}$ & $\mathrm{f}$ & $\varepsilon_{A}, \varepsilon_{B}$ & $T_{A}, T_{B}$ \\
& $\mathrm{~mm}$ & $\%$ & $\mathrm{kN} / \mathrm{m}$ & $\mathrm{mm}$ & $\%$ & $\mathrm{kN} / \mathrm{m}$ \\
Experimental & 14.1 & 1 & 0.133 & 22.3 & 1.75 & 0.210 \\
Analytical & 11 & 1.35 & 0.183 & 18.6 & 2.11 & 0.254 \\
\hline \hline
\end{tabular}




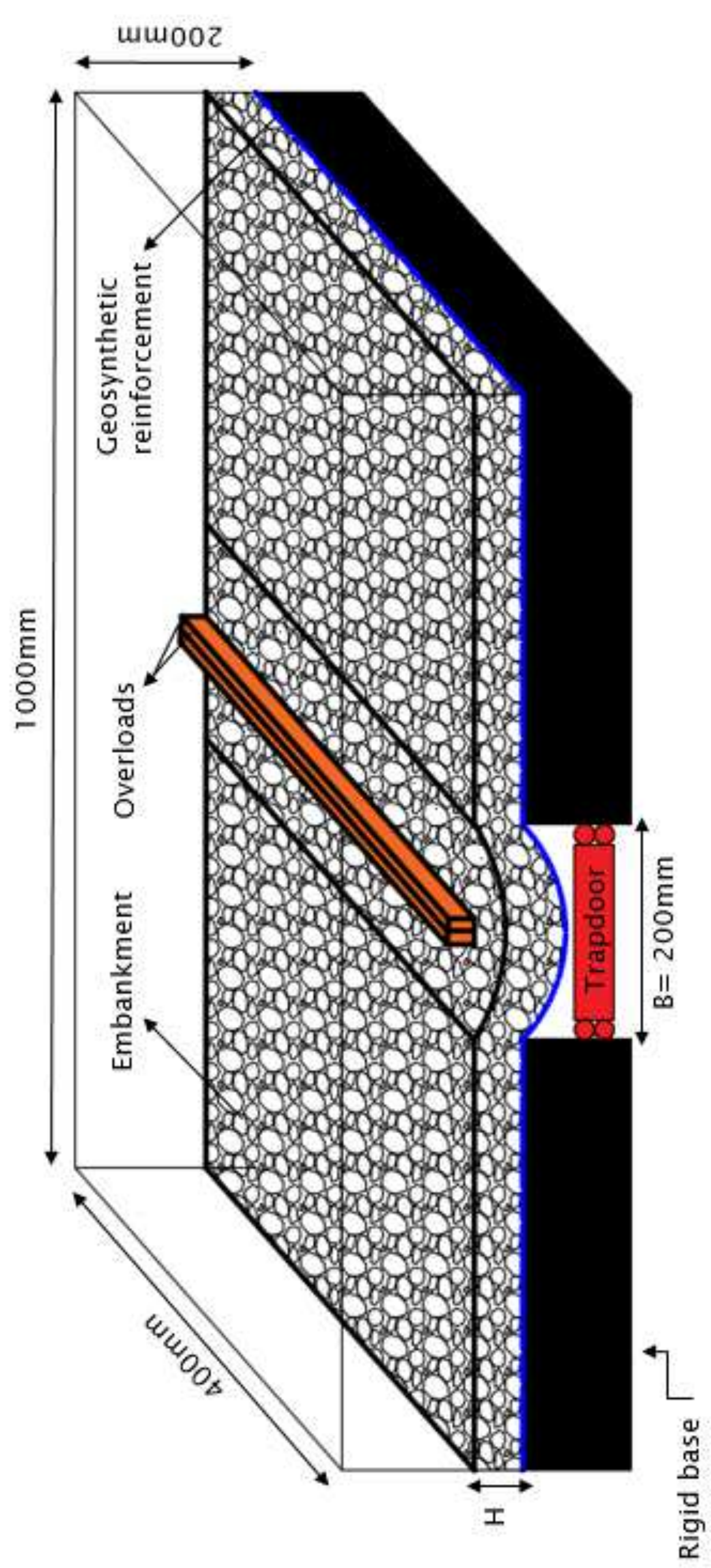




$$
1
$$




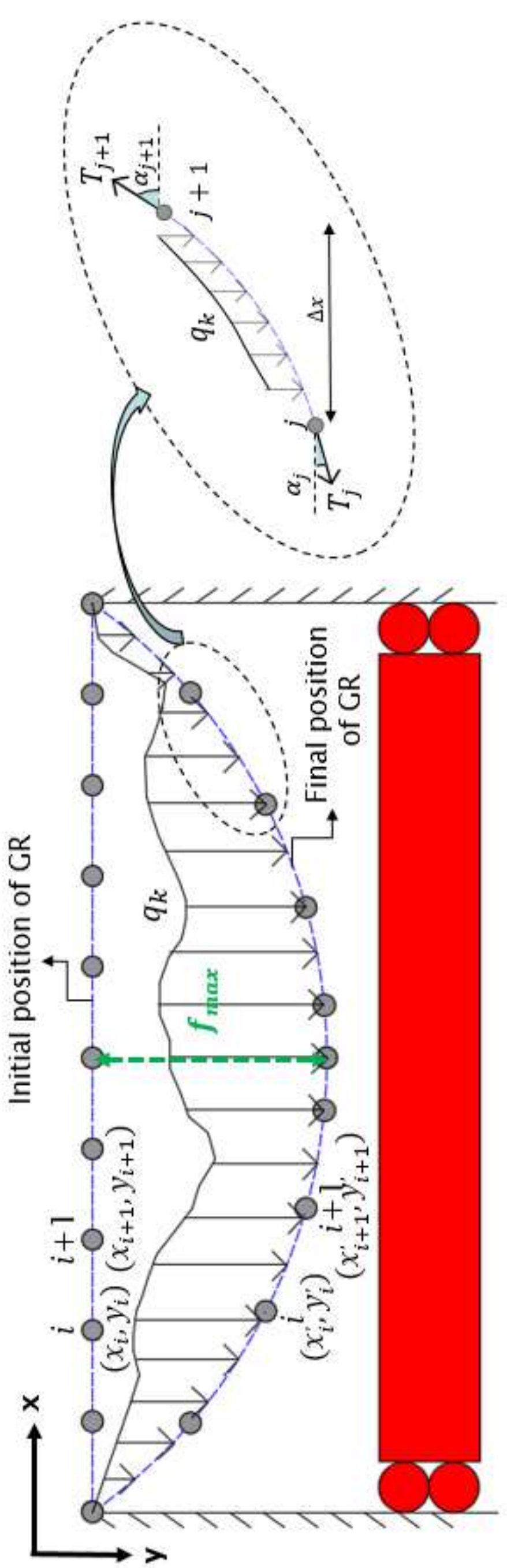


Fig 4

હ̊ํํㅇ
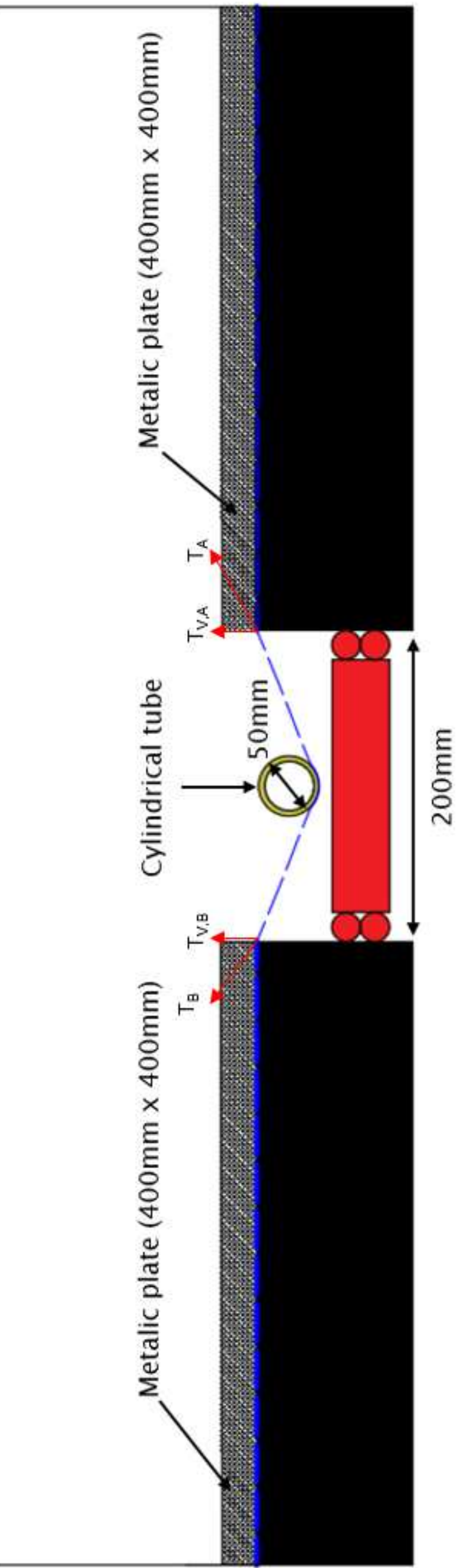


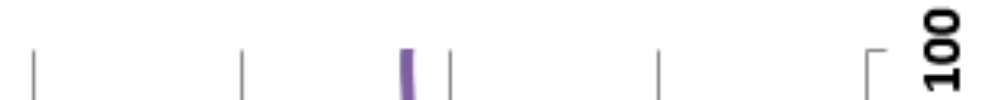

ळ

\&

ब

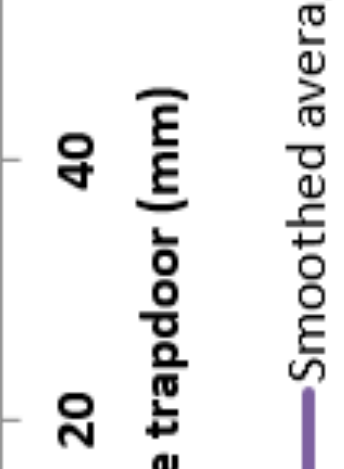
岳

แิ

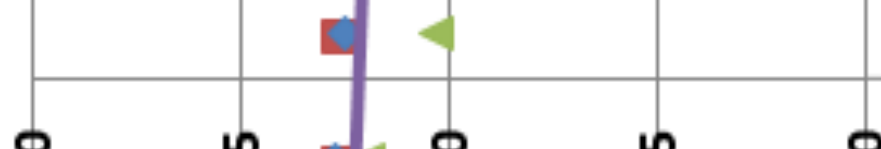

iv

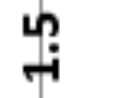

9

\%

○

8

(n)

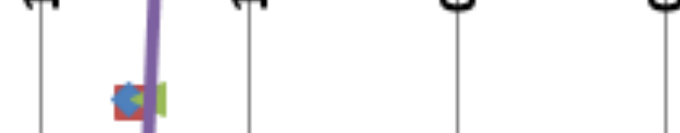

이

들

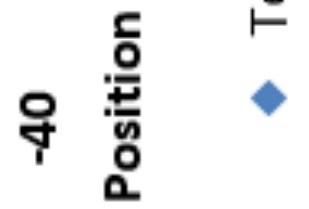

우

$\underset{\frac{\pi}{\infty}}{\frac{\pi}{\infty}}$

๑̊

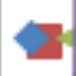

1

פ\% (\%) uịedzs

욱 
Fig $5 b$

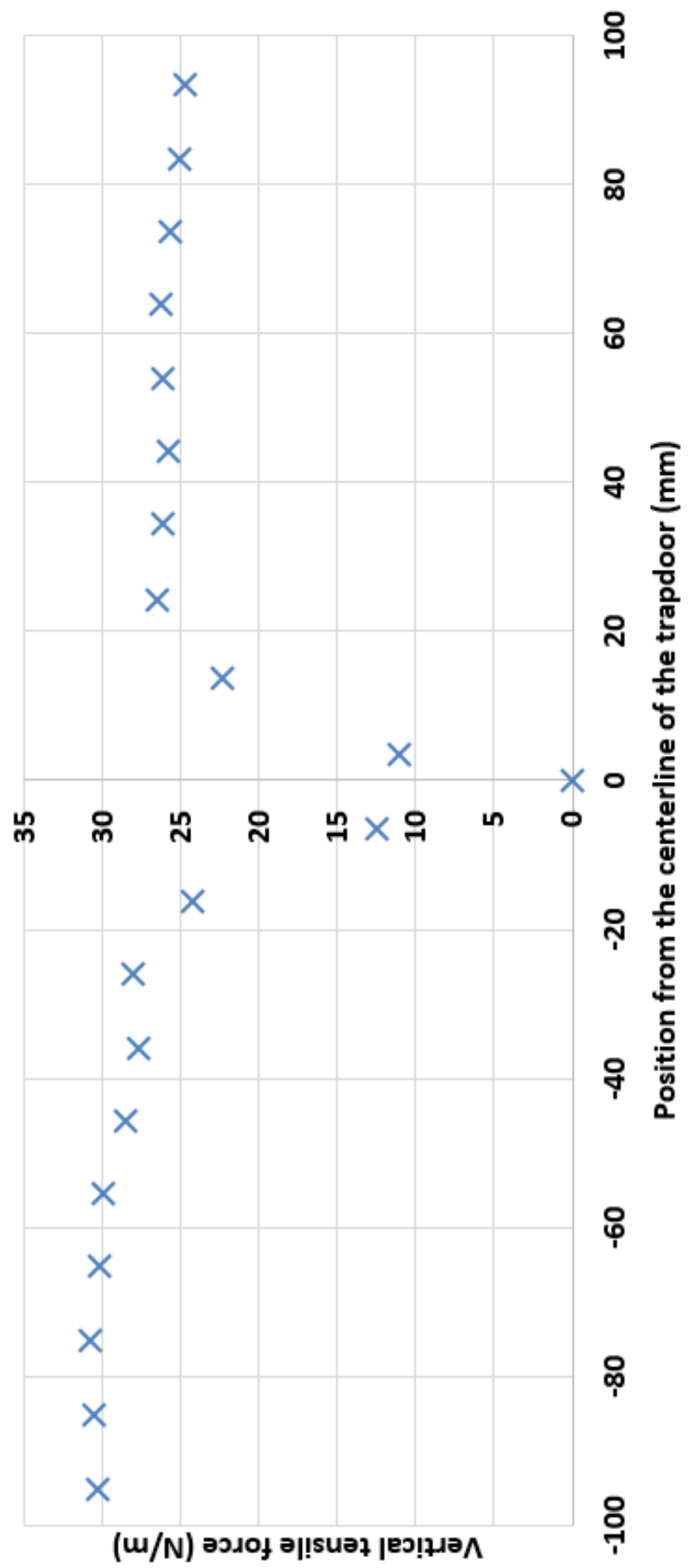




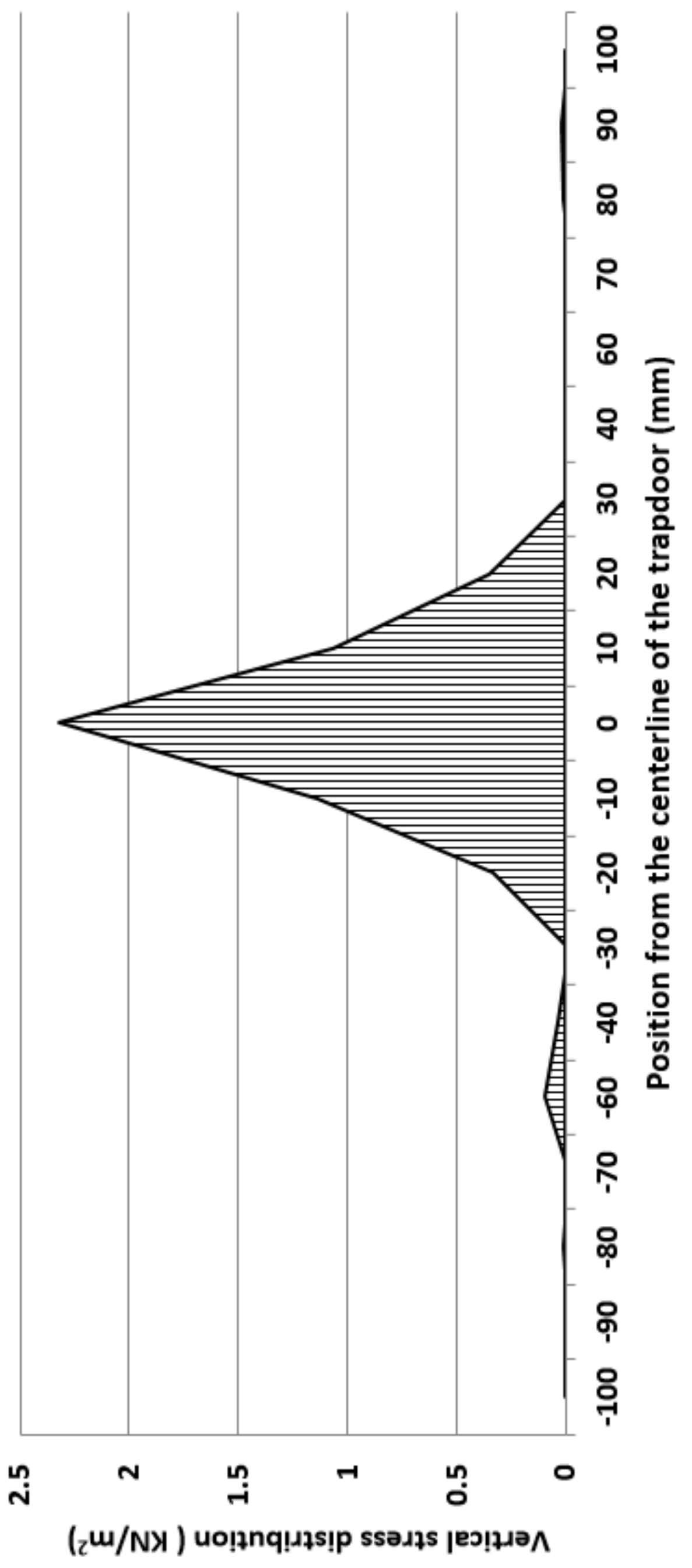


II

I

t
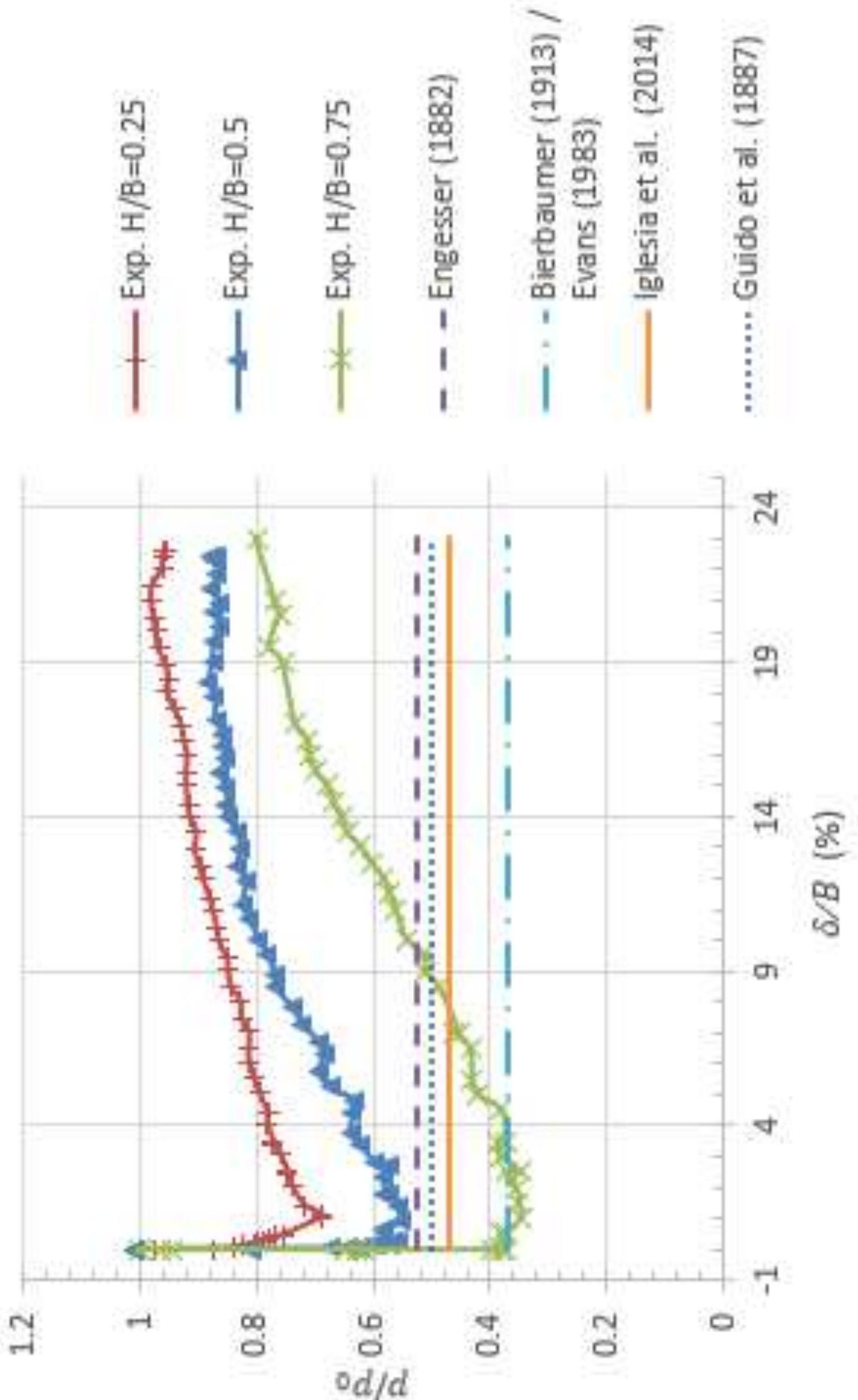
Fig 7
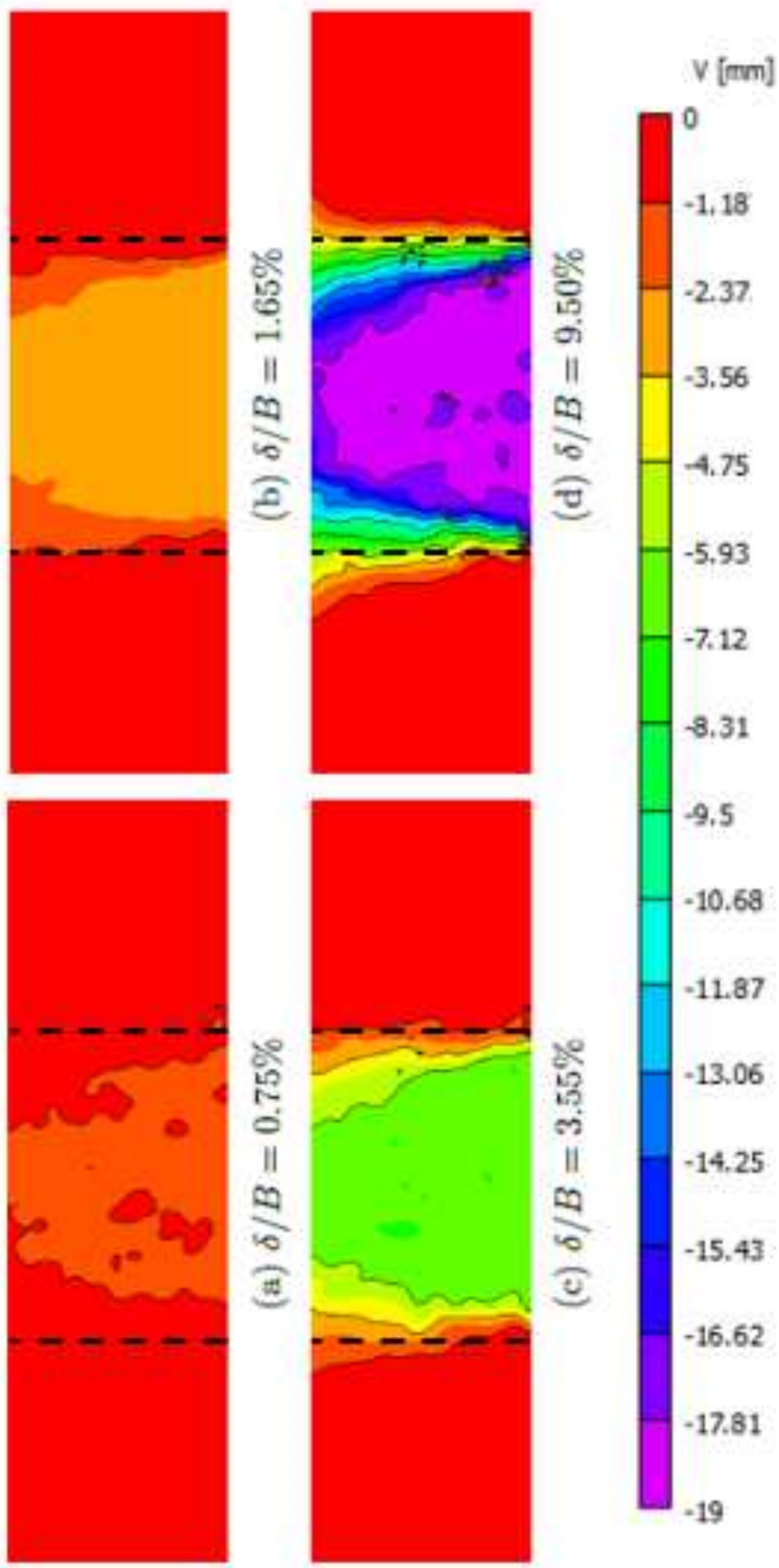

$-7.12$

$-8.31$

$-5,93$

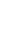

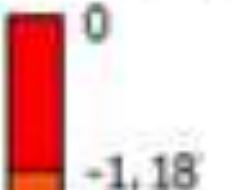

$-2.37$

$-3.56$

$-4.75$

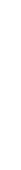

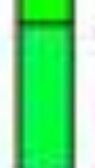

$-10.68$

$-11.87$

$-13.06$

$-14.25$

$-15.43$

$-16.62$

$-17.81$ 


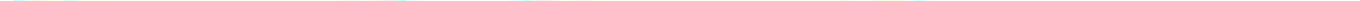


Fig 9

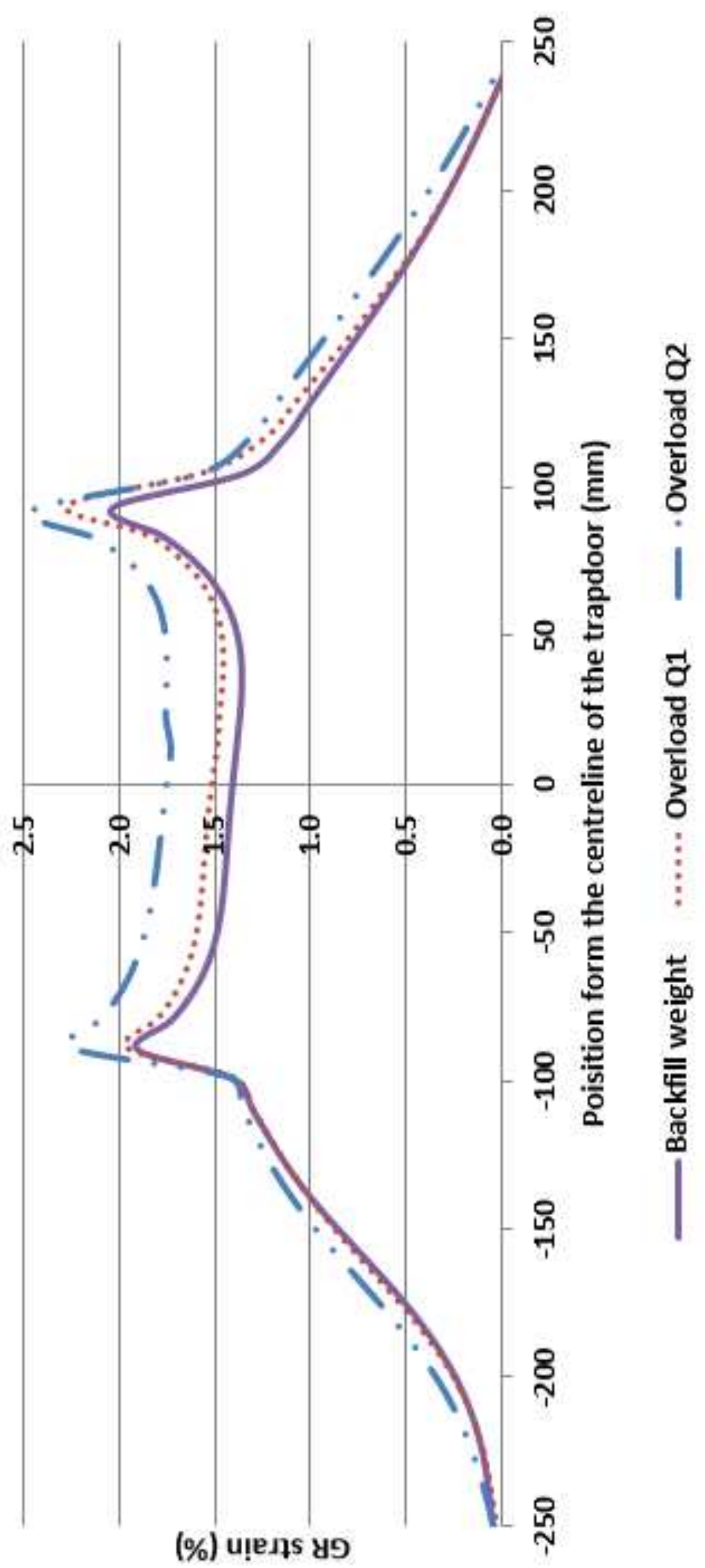


Fig 10

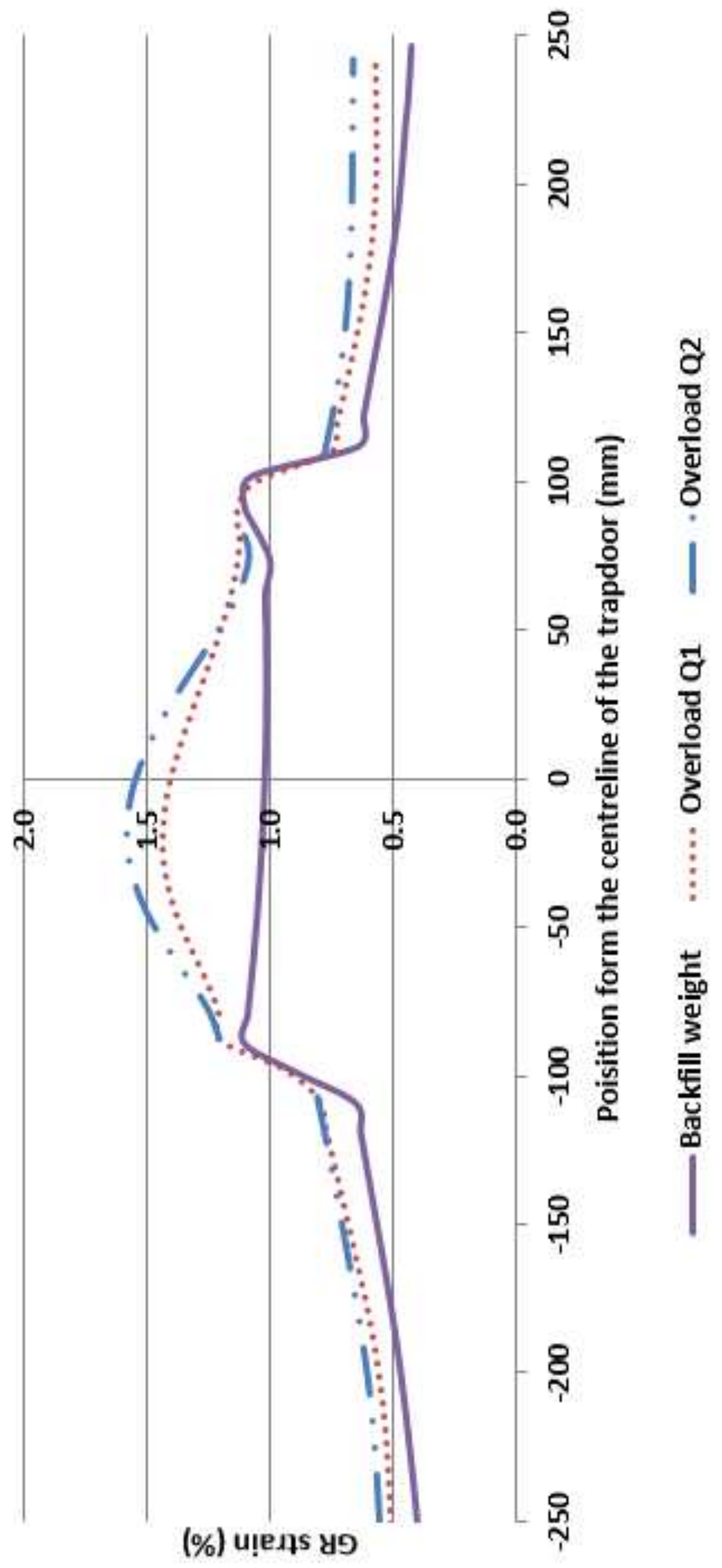




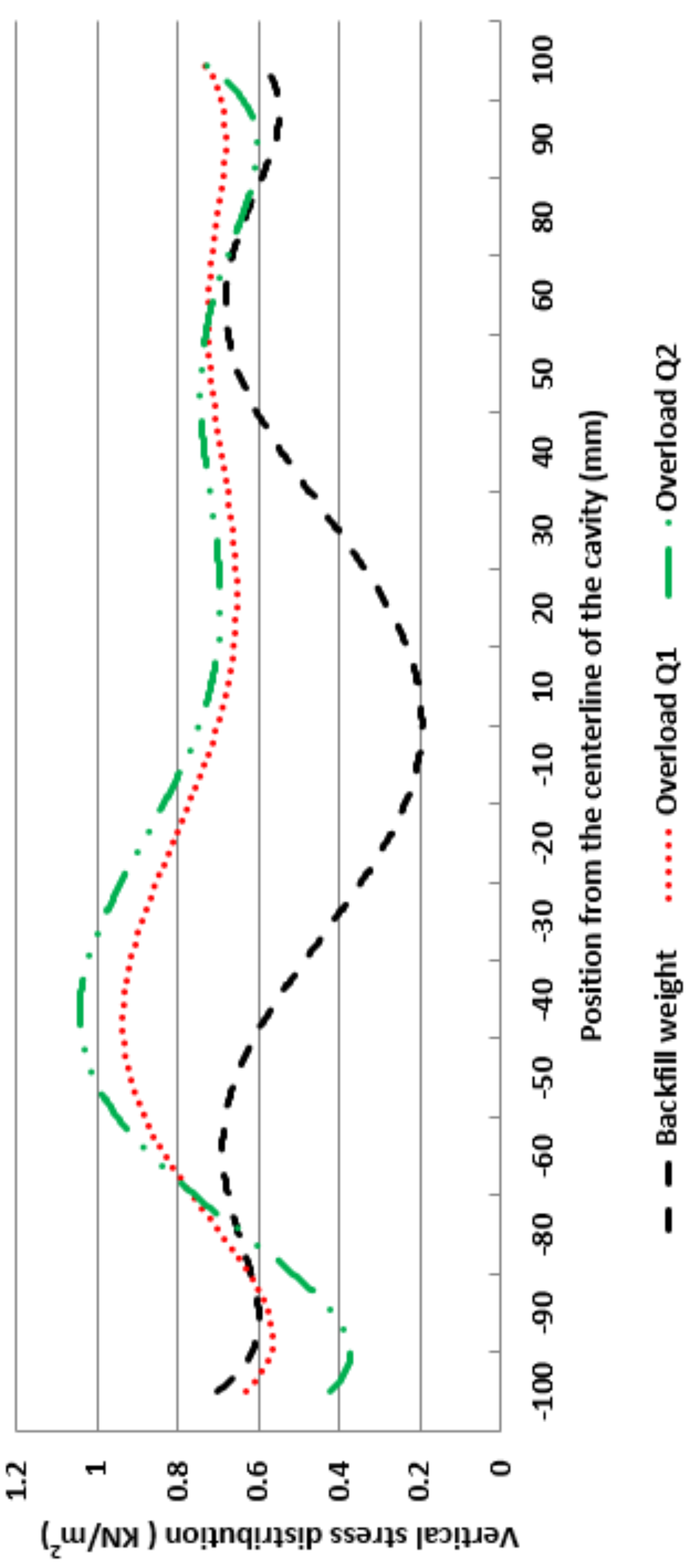


Fig 13
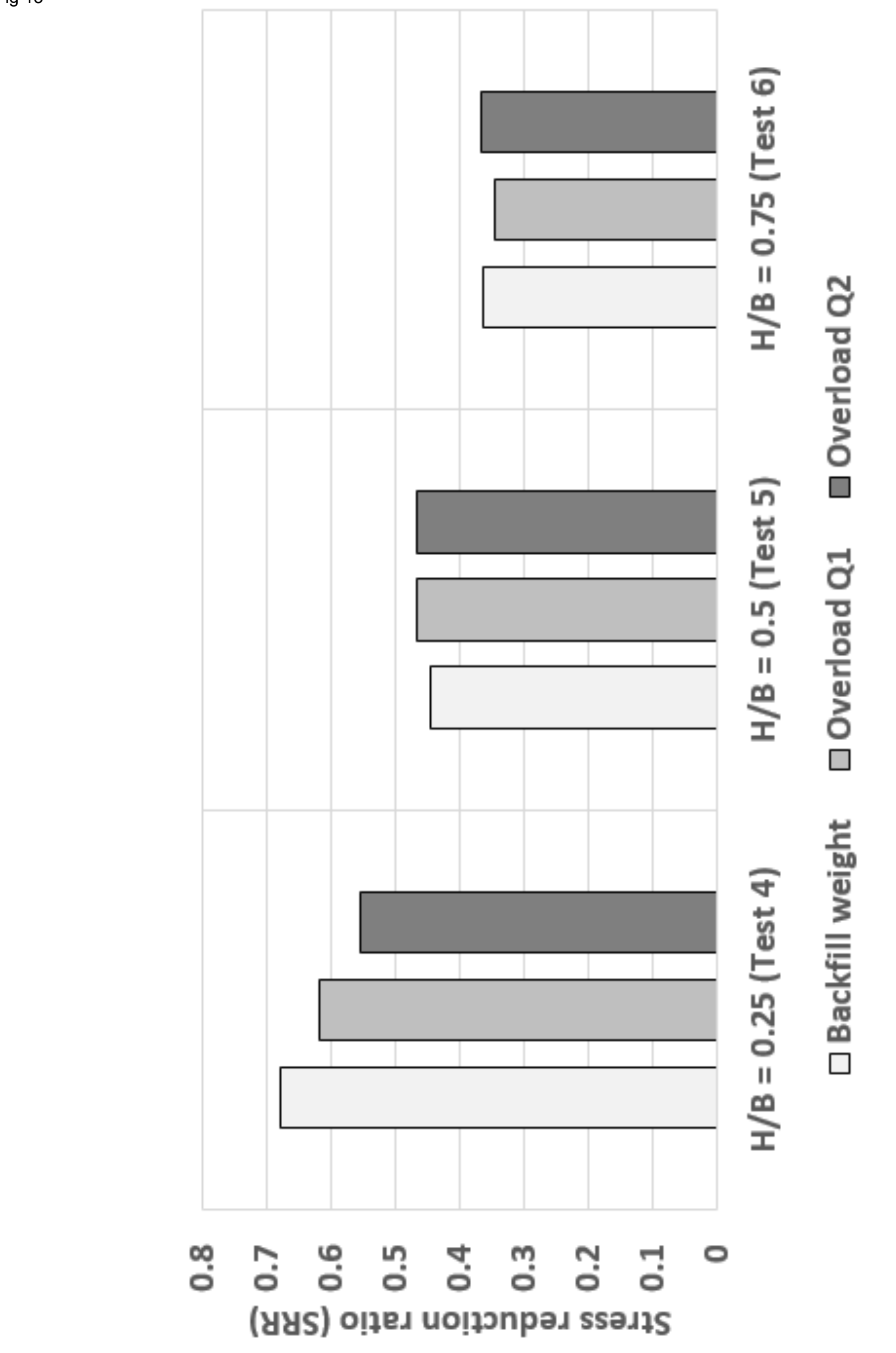

g 13 


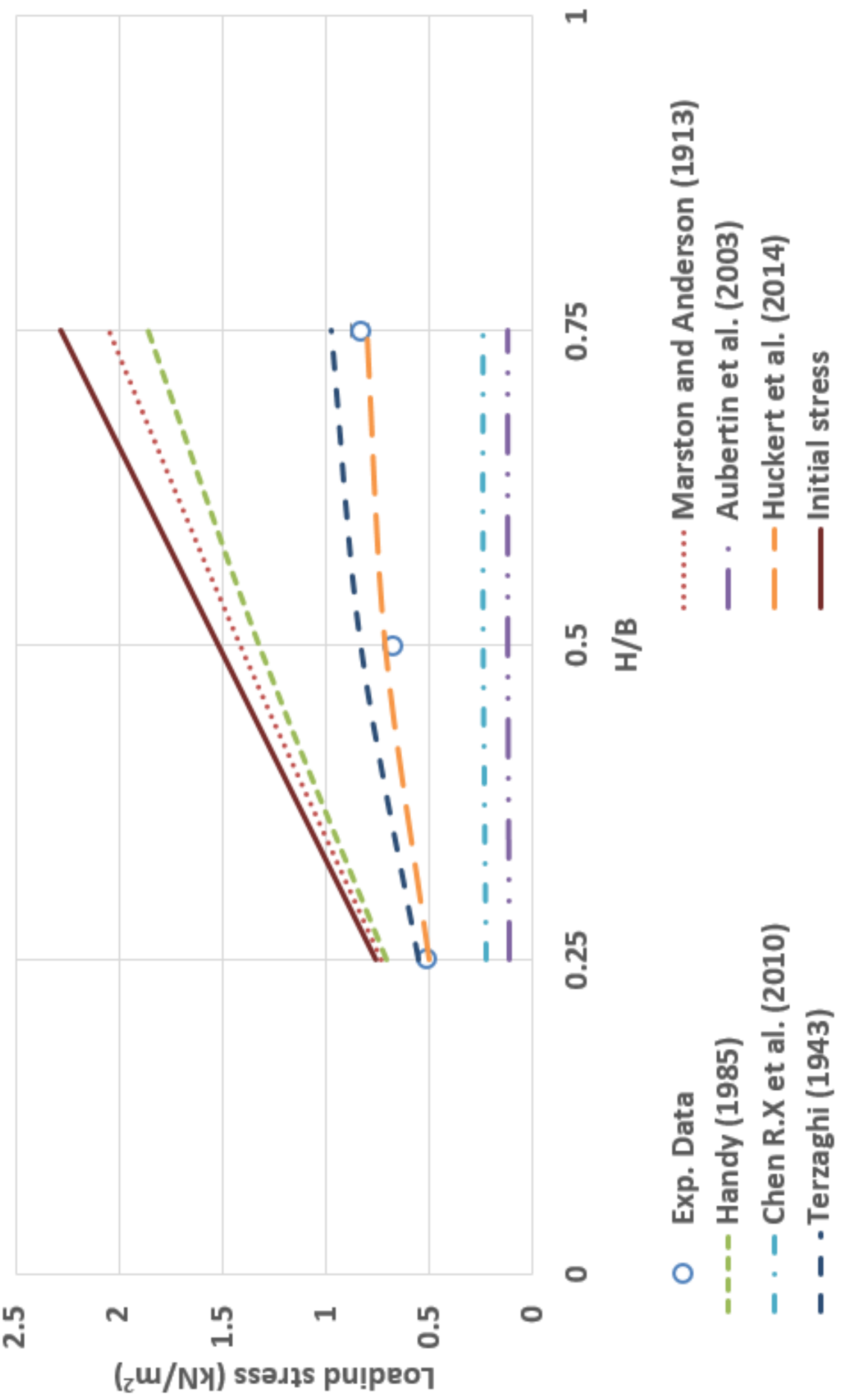




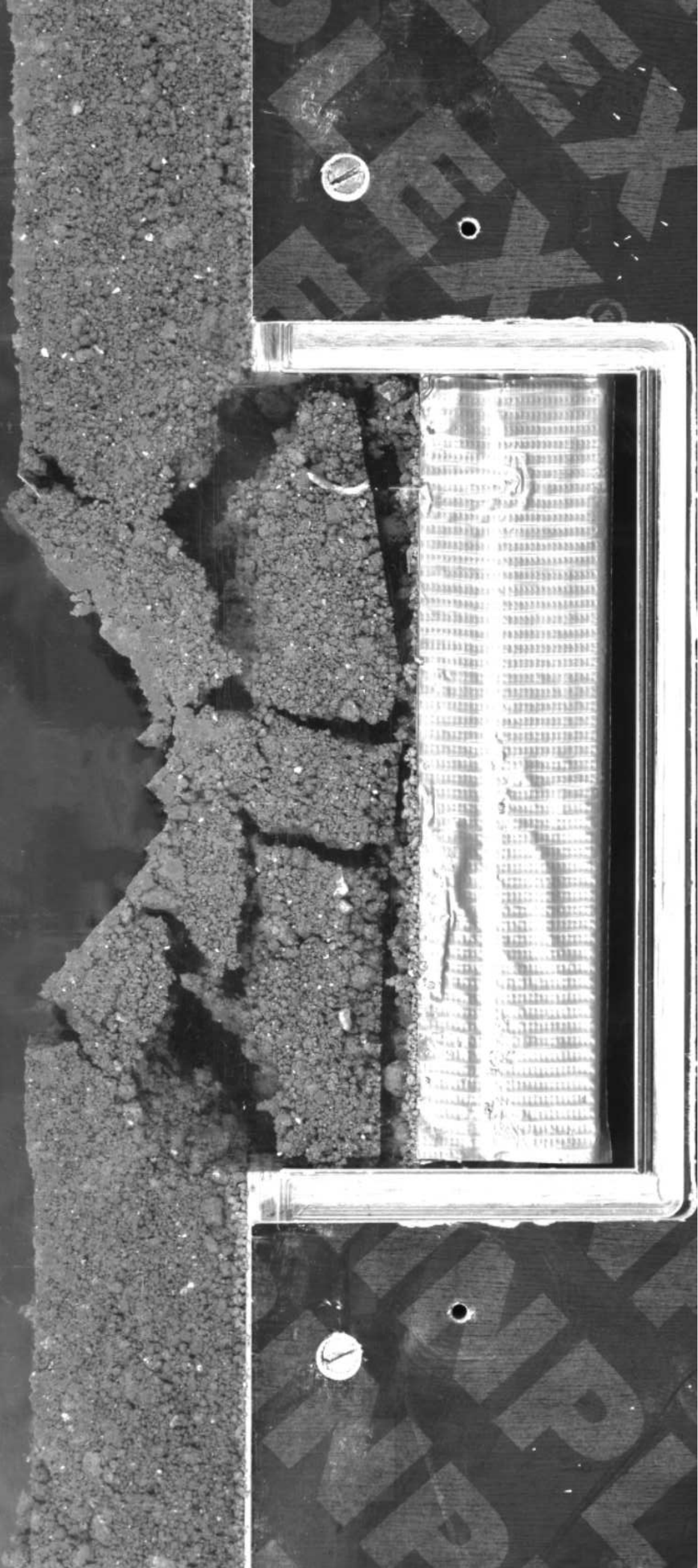




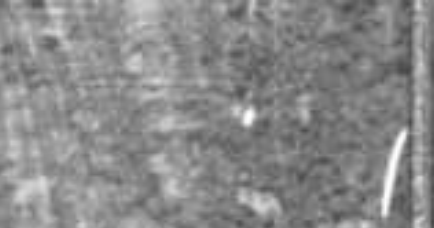

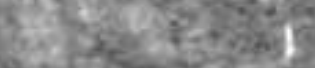

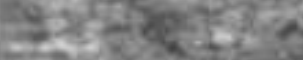

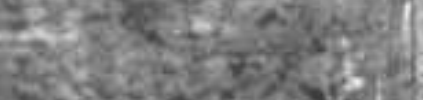

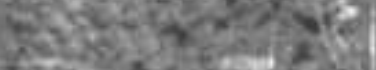

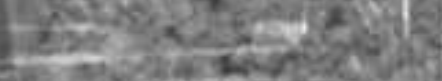

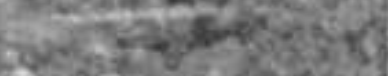
$x^{2}+2=$
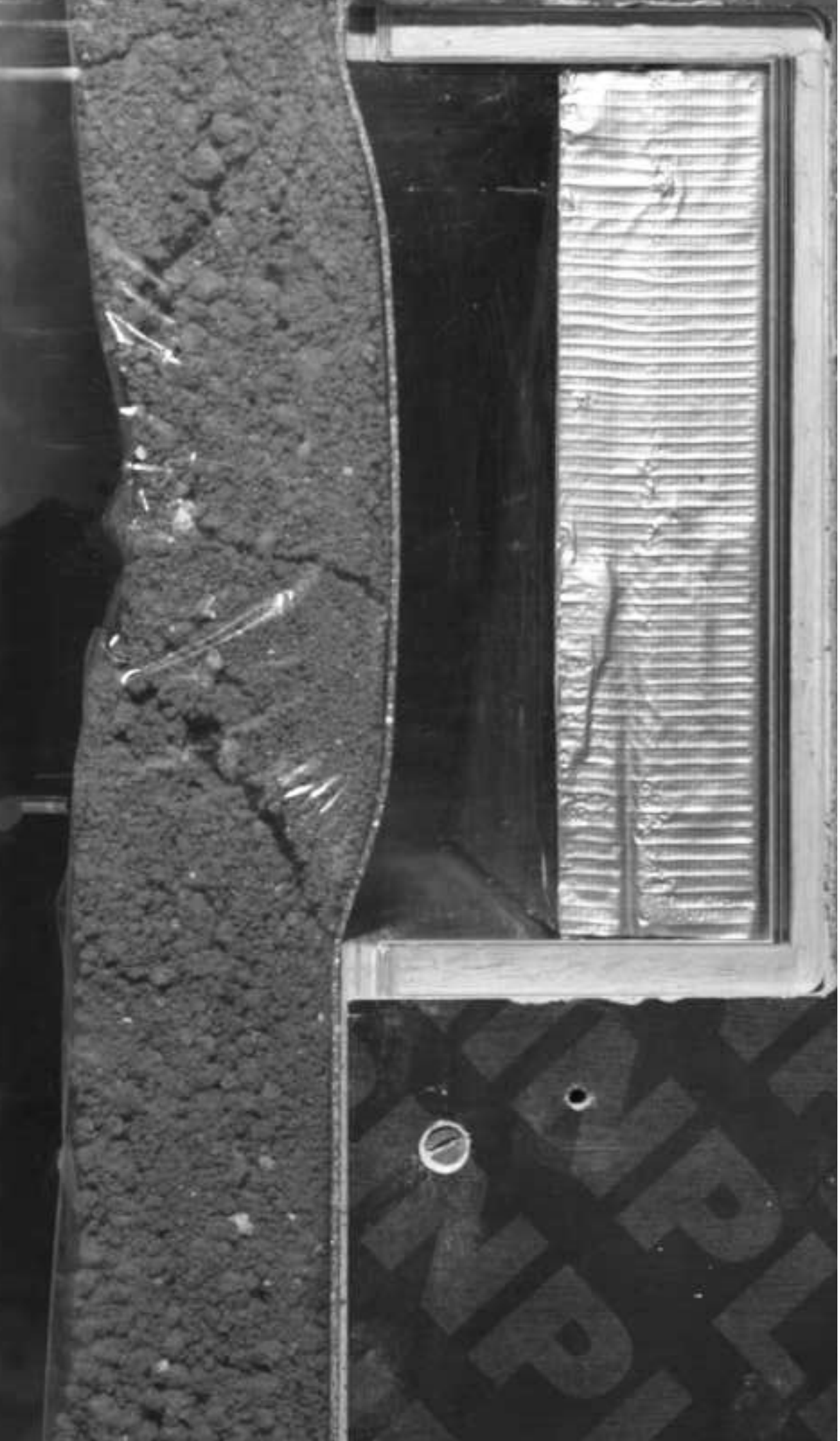

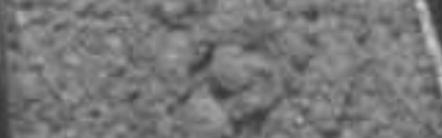

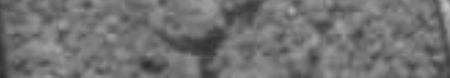

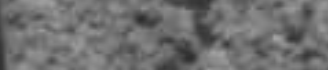

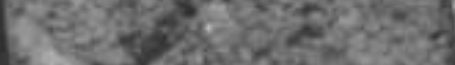

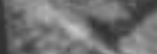
$\sin ^{2} \sin ^{2}$ $\mathrm{W}_{2}$

$\cos ^{2}$

tes:

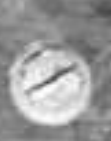

hy 89288 


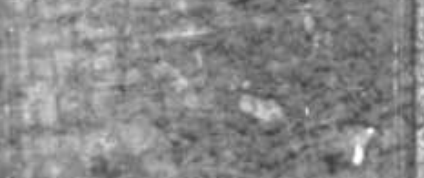

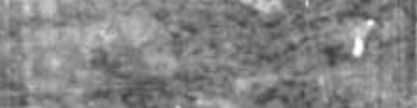

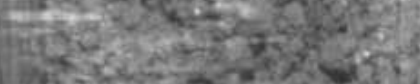

of

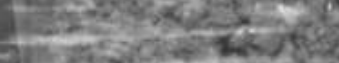

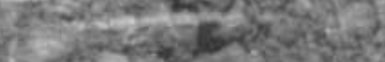

extryes
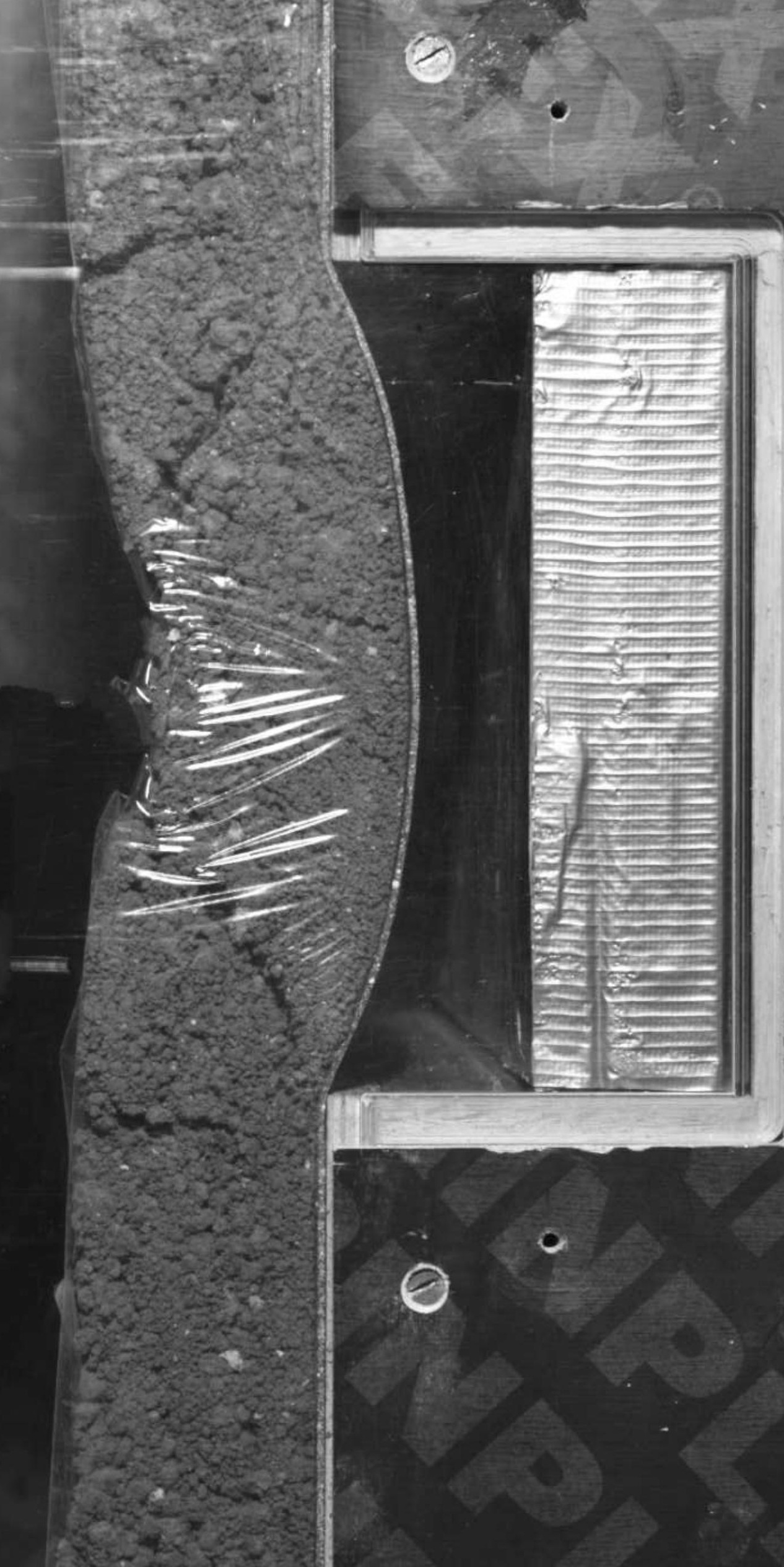

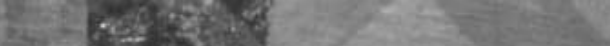




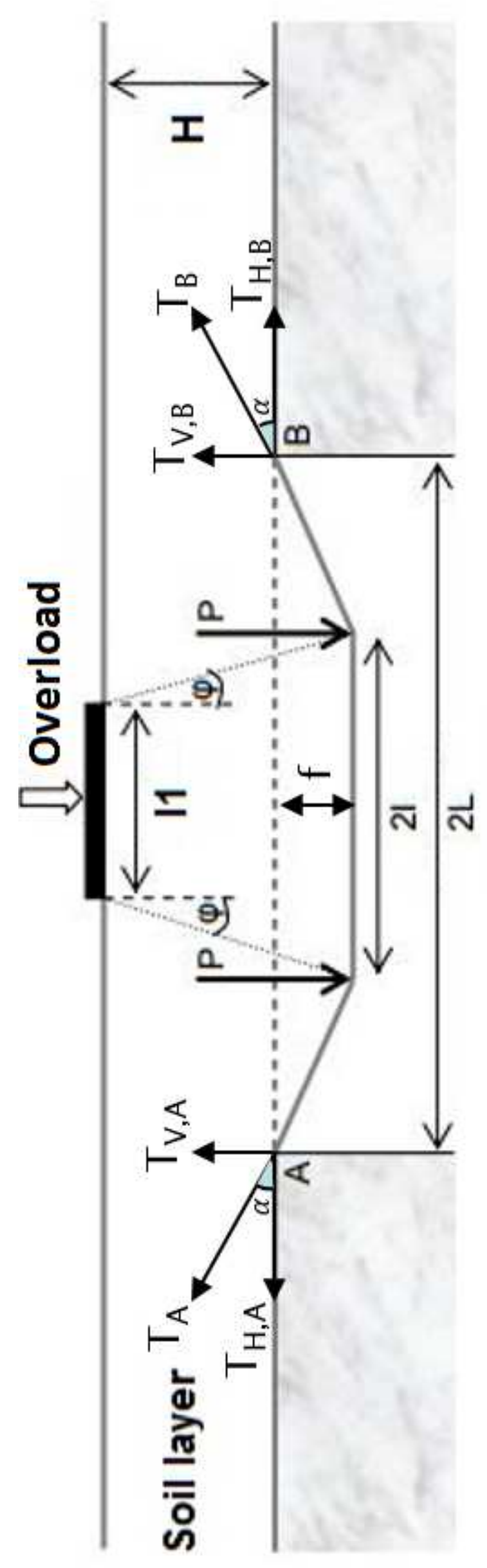

Fig 19
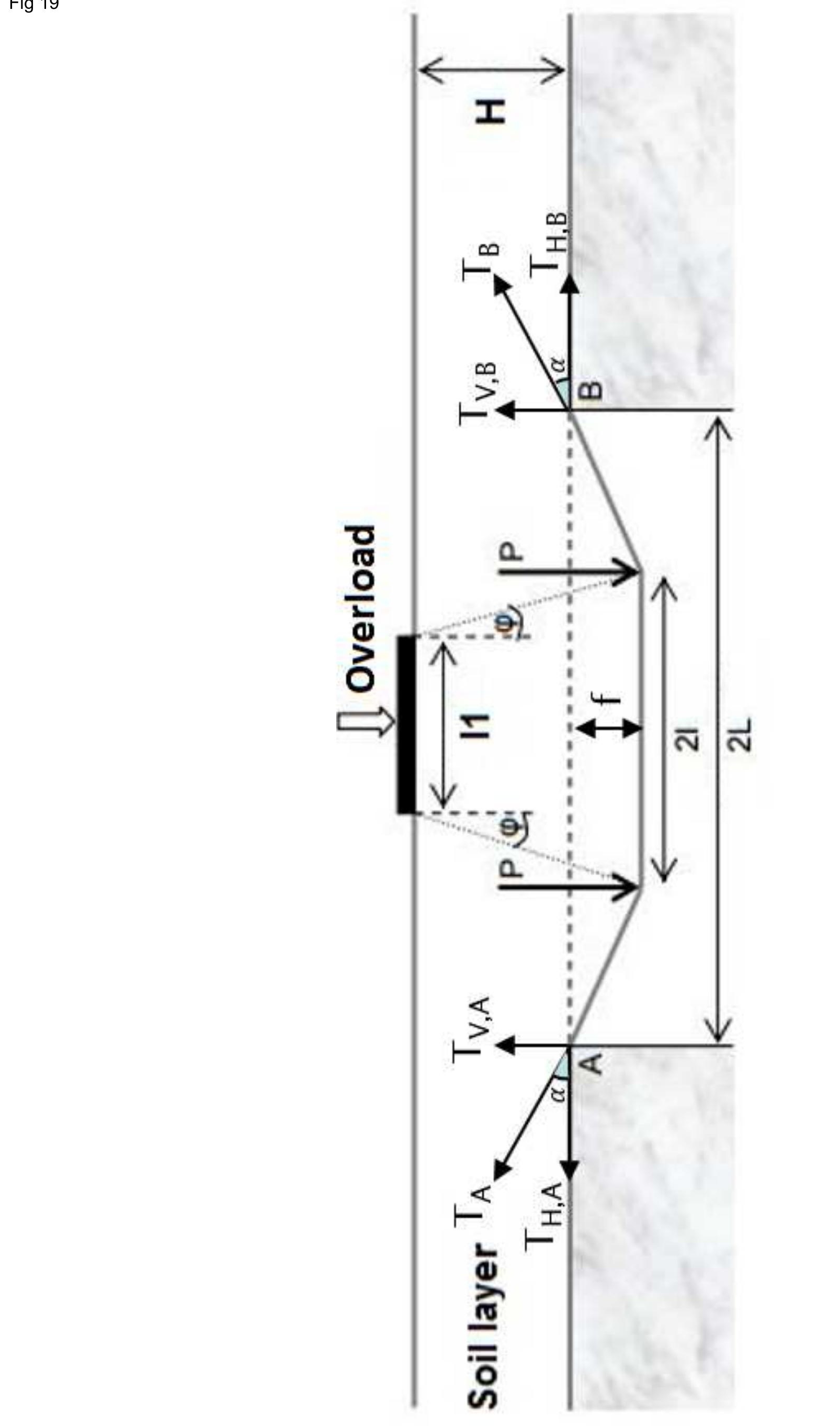


\section{Figure Caption list:}

Fig. 1. Experimental model - Trapdoor

Fig. 2. Evolution of GR axial stiffness with tensile

Fig. 3. Initial and final positions of the GR layer

Fig. 4. Validation test configuration.

Fig. 5. Experimental validation results

Fig. 5a. Tensile strain distribution repeatability of validation

Fig. 5b. Vertical tension distribution above trapdoor for the average smoothed tensile strain curve

Fig. 5c. Vertical stress distribution above trapdoor for the average smoothed tensile strain curve

Fig. 6. Normalized stress evolution with trapdoor displacement

Fig. 7. Vertical displacement evolution with trapdoor displacement of unreinforced and unloaded granular embankment of $\mathrm{H} / \mathrm{B}=0.75$ in Test-3 (vertical dashed lines indicate the trapdoor position

Fig. 8. Vertical displacement evolution with trapdoor displacement of reinforced and unloaded granular embankment of $\mathrm{H} / \mathrm{B}=0.75$ in Test- 6 (vertical dashed lines indicate the trapdoor position)

Fig. 9. Tensile strain distribution evolution with loading over void and in the anchorage zones for Test $6(H / B=0.75)$

Fig. 10. Tensile strain distribution evolution with loading over void and in the anchorage zones for Test $4(\mathrm{H} / \mathrm{B}=0.25)$

Fig. 11. Evolution with loading of vertical stress distribution transmitted to GR for Test $6(H / B=0.75)$ 
Fig. 12. Evolution with loading of vertical stress distribution transmitted to GR for Test 4

$(H / B=0.25)$

Fig. 13. Load transfer variation with embankment height and surface loading for Tests 4-6

Fig. 14. Comparison of average stress results for various $\mathrm{K}$ expressions versus experimental measurements

Fig. 15. Unreinforced cohesive backfill behavior over trapdoor Test $7(H / B=0.25)$

Fig. 15a. Unreinforced cohesive embankment bridging trapdoor void

Fig. 15b. Unreinforced cohesive embankment collapse due to surface loading

Fig. 16. Reinforced cohesive backfill behavior under loading in Test $8(H / B=0.25)$

Fig. 16a. Reinforced cohesive soil layer collapse under $Q_{1}$

Fig. 16b. Reinforced cohesive soil layer collapse under $Q_{2}$

Fig. 17. GR tensile strain distribution over trapdoor and the anchorage zones due to cohesive backfill surface loading in Test $8(\mathrm{H} / \mathrm{B}=0.25)$

Fig. 18. Vertical stress distribution on GR over trapdoor due to cohesive backfill surface loading in Test $8(\mathrm{H} / \mathrm{B}=0.25)$

Fig. 19. Model proposed by Huckert et al. (2014) to design the GR layer under collapsed cohesive embankments 